\title{
Iraklılık Kimliği: Irak’ta Kimliğin Alternatif Tarihi
}

\author{
Tunahan Y1ldı*
}

\section{Öz}

Irak’ta kimlik meselesi çoğunlukla yapaylık varsayımı üzerinden tartışılmaktadır. $\mathrm{Bu}$ ana akım yapaylık tezi, devlet-altı ve devlet-üstü kimlikleri önceleyerek devlet kimliğinin yokluğunu veya güçsüzlüğünü ispatlamaktan ziyade bu kimliğin üstünü örtmektedir. Bu makale, Irak'ta devlet kimliğinin mevcudiyetini, nüfuzunu ve kapsamını tarihsel ve güncel yansımaları üzerinden araştırmaktadır. Makale, Iraklılığın diğer aidiyet boyutlarının yanında bir alternatif teşkil edip etmediğini, bu kimliğin hangi yollarla kurgulandığını ve siyasî ve toplumsal olarak nasıl bir karşılığa sahip olduğunu araştırmaktadır. Bu anlamda, Irak siyasetini ve toplumunu tarihsel olarak okumanın ana paradigması olan yapaylık tezine karşılık Iraklılık kimliği üzerinde konumlandırılan bir bakışın Irak’ta kimliğin tarihini alternatif bir yoldan okuma imkânı verdiği ve alternatif bir kimlik tarihi ortaya çıkardığı savunulmaktadır. Bu okuma neticesinde bu kimlik tarihine dair birbiriyle alakalı dört farklı sonuca ulaşılmaktadır: İlk olarak, incelenen tarih içerisinde Iraklılığın önemli bir ideolojik/kültürel etken olarak hazır bulunduğu görülmektedir. İkinci olarak, Iraklılığın Irak’taki diğer aidiyet boyutlarıyla çoğu zaman bir etkileşim içerisinde olduğu gözlemlenmektedir. Üçüncü olarak, dönemlere ve aktörlere bağlı biçimde Iraklılığın kurgulanışında önemli farklılaşmalar tespit edilmektedir. Dördüncü olarak, Iraklılığın devletin ve seçkinlerin politikalarının ötesinde toplumsal yayılımı gözetilmektedir.

Anahtar Kelimeler: Irak, Iraklılık, Milli Kimlik, Devlet Kimliği, Yapaylık

Arş. Gör., Ortadoğu Teknik Üniversitesi, TR, Uluslararası İlişkiler Bölümü, orcid. org/0000-0002-2516-8024, tunahan@metu.edu.tr 


\title{
The Iraqi Identity: An Alternative History of Identity in Iraq
}

\author{
Tunahan Y1ldiz
}

\begin{abstract}
The issue of identity in Iraq has been debated usually through the lens of the artificiality assumption. This mainstream thesis assumes an absence or weakness of the state/national identity and prioritizes sub-state and supra-state identities. This article examines the existence, scope and content of the national identity in Iraq through its historical and current manifestations. It questions whether the Iraqi identity has constituted an alternative dimension of belonging among the multiple identities of Iraq, in which ways this identity is imagined and constructed, and how it is performed in social and political domains. In this context, it argues that an examination of the Iraqi identity gives an alternative reading of the history of identity in Iraq. Such a reading draws four interrelated conclusions: First, the Iraqi identity has been an important ideological/cultural factor in Iraqi history. Second, Iraqiness has often been in interaction with other identity dimensions. Third, there have been significant differentiations of the imaginations of the Iraqi identity depending on the period and actors. Last, the Iraqi identity has extended beyond the policies of the state and elites and has expanded into the Iraqi society.
\end{abstract}

Keywords: Iraq, Iraqiness, National Identity, State Identity, Artificiality

* Res. Asst., Middle East Technical University, The Department of International Relations, orcid.org/0000-0002-2516-8024, tunahan@metu.edu.tr 


\section{Giriş}

Irak siyasî tarihinin yazımında, devlet-altı ve devlet-üstü kimliklerin devlet kimliğine ciddi meydan okumalar getirdiği ve sıklıkla üstün geldiği çokça tartışılmış olup Irak'ın yapaylığ 1 hayli popüler biçimde vurgulanmıştır. ${ }^{1}$ Hatta Irak, Orta Doğu'da çokça şahit olunan kimlik çatışmalarının ve uyumsuzluğunun başlıca örneklerinden biri olarak sıklıkla öne çıkarılmaktadır. ${ }^{2}$ Bu geleneksel bakış açısına göre devlet kimliği, "yapay” olduğu için (yani dışarıdan ve yukarıdan dayatıldığı için) büyük oranda başarısız, gelişmemiş ya da en iyi ihtimalle zayıf görülmektedir. Bir başka ifadeyle, çok-unsurlu Irak toplumunun ortak kimlik paydası ya yoktur ya da çok dardır ve bu "kusurlu" temel üzerine kurulu Irak'ın sürekli istikrarsız olması neredeyse kaçınılmazdır. Bu anlatı, basitçe, 2003 işgali öncesi için devletle yan yana olan Sünniler ve devlete muhalif olan Şiiler tablosu çizerken, 2003 sonrası için de bu tabloyu tersine çevirmektedir.

Ancak bu yapaylık tezi, Irak'ın (işlevsel sorunlar yaşasa da yapısal olarak) bir ulus-devlet olduğunu yadsımakta, Irak vatandaşlarının kendi devletlerinin kimliğiyle bir bağı olmadığını varsaymakta, bugünün Irak'ına bakarken yaklaşı yüzyıllık ulus-devletlik tecrübesini reddetmekte, ulus-

Bazı örnekler için bakınız: Michael M. Gunter, The Kurds of Iraq: Tragedy and Hope (New York: St. Martin's Press, 1992); Michael Eppel, "The Elite, the Efendiyya, and the Growth of Nationalism and Pan-Arabism in Hashemite Iraq, 1921-1958," International Journal of Middle East Studies 30, no. 2 (1998): 227-250; Toby Dodge, Inventing Iraq: The Failure of Nation-Building and a History Denied (New York: Columbia University Press, 2003); Christopher Catherwood, Churchill's Folly: How Winston Churchill Created Modern Iraq (New York: Carrol \& Graf, 2004); Liam Anderson and Gareth Stansfield, The Future of Iraq: Dictatorship, Democracy, or Division? (New York: Palgrave Macmillan, 2004); Peter W. Galbraith, The End of Iraq: How American Incompetence Created a War Without End (New Jersey: Simon \& Schuster, 2006); Ivan Eland, Partitioning for Peace: An Exit Strategy for Iraq (Oakland: The Independent Institute, 2009); Marco Vicenzino, "Iraq's Muddled Future," Huffington Post, April 17, 2015, https://www.huffingtonpost.com/marcovicenzino/iraqs-muddled-future_b_7081106.html; "Iraq PM Slams U.S. Officer's Remarks on Partition," Al Arabiya English, August 13, 2015, http://english.alarabiya. net/en/News/middle-east/2015/08/13/Departing-U-S-army-chief-Iraq-may-have-tobe-partitioned.html.

2 Tipik iki örnek için bakınız: Reinoud Leenders, "Strong States in a Troubled Region: Anatomies of a Middle Eastern Regional Conflict Formation," in Troubled Regions and Failing States: The Clustering and Contagion of Armed Conflict, ed. Kristian Berg Harpviken (Oslo: Emerald Group Publishing, 2010), 171-195; Alex Danilovich, Iraqi Federalism and the Kurds: Learning to Live Together (Surrey: Ashgate Publishing, 2014), 4. 
devletin Irak'taki mevcut bağlamında neden genellikle sorgulanmadığını yanıtlayamamakta ve devlet-altı ve devlet-üstü kimliklerin de inşa edildiğini unutarak bu kimliklere aslında mevcut olmayan bir doğallık ve normallik atfetmektedir. ${ }^{3}$ Dolayısıyla bu ana-akım yaklaşım, devlet kimliğinin yokluğunu veya güçsüzlüğünü ispatlamaktan ziyade bu kimliğin üstünü örtmektedir. Bu anlamda, Irak'ta devlet kimliğinin varlığını, kurgulamalarını ve yansımalarını incelemek oldukça önemlidir. Böylesi bir inceleme, Irak’ta kimliğin tarihini hâkim paradigmanın karşısında alternatif bir yoldan okuma imkânı vermektedir.

Bahsedilen ana-akım yaklaşımın dışına çıkarak devlet kimliğine vurgu yapan önemli çalışmaları, Irak’a dair İngilizce literatürde bulmak mümkündür. ${ }^{4}$ Ancak bu kimliğin, Irak'1n kuruluşunun öncesinden başlayarak bugüne uzanan uzun soluklu bir incelemesi yapılmamıştır. Genel itibarıyla Türk akademisi ise (muhtemelen yukarıda bahsedilen yapaylık varsayımlarına dayanarak) Iraklılık kimliğini bir araştırma konusu haline getirmemiştir. Oysa ki Irak’taki devlet inşası süreci, ulus oluşumu sürecinden ayrı tutula-

Fanar Haddad and Sajjad Rizvi, "Fitting Baghdad in," in An Iraq of its Regions: Cornerstones of a Federal Democracy, eds. Reidar Visser and Gareth Stansfield (London: Hurst \& Company, 2007), 51-52.

4 Amatzia Baram'ın çalışmaları, bilhassa Baas döneminde antik ögelerle devlet kimliği arasında kurulan bağlantıları aydınlatmaktadır: Amatzia Baram, "A Case of Imported Identity: The Modernizing Secular Ruling Elites of Iraq and the Concept of Mesopotamian-Inspired Territorial Nationalism, 1922-1992," Poetics Today 15, no. 2 (1994): 281-292; Amatzia Baram, "Mesopotamian Identity in Ba'thi Iraq," Middle Eastern Studies 19, no. 4 (1983): 426-455; Amatzia Baram, "Territorial Nationalism in the Middle East," Middle Eastern Studies 26, no. 4 (1990): 425-448; Amatzia Baram, Culture, History and Ideology in the Formation of Bathist Iraq, 1968-89 (London: Palgrave Macmillan, 1991); Amatzia Baram, "Qawmiyya and Wataniyya in Ba'thi Iraq: The Search for a New Balance," Middle Eastern Studies 19, no. 2 (1983): 188-200. Adeed Dawisha'nın çalışmaları, mezhep kimlikleri ile Iraklılık arasındaki etkileşime dair farklı zaman kesitlerinden bulgular sunmaktadır: Adeed Dawisha, "National Identity and Sub-State Sectarian Loyalties in Iraq," International Journal of Contemporary Iraqi Studies 4, no. 3 (2010): 243-256; Adeed Dawisha, "The Unraveling of Iraq: Ethnosectarian Preferences and State Performance in Historical Perspective," Middle East Journal 62, no. 2 (2008): 219-230; Adeed Dawisha, "Identity and Political Survival in Saddam's Iraq," Middle East Journal 53, no. 4 (1999): 553-567; Adeed Dawisha, "Iraq: A Vote Against Sectarianism," Journal of Democracy 21, no. 3 (2010): 26-40. Fanar Haddad'ın çalışması da Irak'taki Sünni ve Şii mezhepçilikleri birbiriyle rekabet halindeki Irak milliyetçiliği türleri olarak tasvir etmektedir: Fanar Haddad, Sectarianism in Iraq: Antagonistic Visions of Unity (Oxford: Oxford University Press, 2011). 
maz. ${ }^{5}$ Bu makale, devlet kimliğinin mevcudiyetini, nüfuzunu ve kapsamını tarihsel ve güncel yansımaları üzerinden araştırmaktadır. Bir başka deyişle, Iraklılığın diğer aidiyet boyutlarının yanında bir alternatif teşkil edip etmediği, bu kimliğin hangi yollarla kurgulandığı ve siyasî ve toplumsal olarak nasıl bir karşılığa sahip olduğu araştırılmaktadır. Aşağıda takip eden bölümlerde Iraklılığın belirgin kılındığı tarihsel anlar ve süreçler incelenmektedir. Bu inceleme, tarihsel olarak sırasıyla kuruluş öncesi, Hâşimî hanedanlığı, cumhuriyet ve işgal sonrası dönemlerini kapsamaktadır.

\section{Devletten Önce Irak ve Iraklılık}

Yapaylık paradigması, Birinci Dünya Savaşı'ndan önce Irak'tan bahsedilemeyeceğini, Irak'ın tarihsel bir derinlikten yoksun olduğunu, ülkenin tamamen İngiltere tarafından icat edildiğini, bu icadın birbiriyle alakası olmayan üç Osmanlı vilayetini bir araya getirerek yapıldığııı iddia etmektedir. Bu klasik paradigmanın varsayımlarının aksine, bir sömürgecilik inşası biçiminde çizilmesinden önce bir bölge olarak Irak'ın nasıl ortaya çıktığına ve nasıl bir devamlılığa sahip olduğuna dair bulgular bulunmaktadır. Öncelikle, Irak kelimesi, Arap coğrafyacılar tarafından en az VIII. yüzyıldan beri Firat ve Dicle arasındaki bölgeye atıf yapılarak kullanılmıştır. ${ }^{6}$ Aslında, XIII. ve XIV. yüzy1llardaki Moğol ve Türk hükümdarlıklarına gelindiğinde Bağdat, kuzeydeki Zagros dağlarından güneydeki körfeze uzanan bölge için bir güç merkezi teşkil etmekteydi. ${ }^{7}$ Gelgelelim bu toprakların esasen Osmanlı idaresinde nispeten geniş bir idarî-siyasî bütünleşmeyi yakaladığı söylenebilir. Osmanlı idaresi altında, Bağdat'ın sınırları bugünkünden çok daha geniş bir hal almıştır; Bağdat, her ne kadar ayrı idarî birimler teşkil etseler de Basra ile daha az oranda Musul için önemli bir merkez işlevi görmüştür ve Osmanlı-Safevi antlaşmalarıyla Irak'ın doğu sınırları aşamalı olarak belirginleşmiştir. ${ }^{8}$ Bir başka ifadeyle,

Serra Can, “The Iraqi Identity: Faisal's Unsolved Legacy,” Trames: A Journal of the Humanities and Social Sciences 22, no. 4 (2018): 390.

6 Charles Tripp, A History of Iraq (Cambridge: Cambridge University Press, 2007), 8.

7 Reidar Visser, "Proto-Political Conceptions of Iraq in Late Ottoman Times," International Journal of Contemporary Iraqi Studies 3, no. 2 (2009): 144.

8 Thabit A. J. Abdullah, Dictatorship, Imperialism and Chaos: Iraq since 1989 (London and New York: Zed Books, 2006), 7; Visser, "Proto-Political Conceptions of Iraq in Late Ottoman Times," 144. 
Bağdat ve çevresi, geç Osmanlı döneminde Bağdat'ın bir nevi başkent olduğu görece bütünleşik bir ön-siyasî yapı haline gelmiştir. ${ }^{9}$ Irak vilayeti olarak adlandırılan bir idarî birim ortaya çıkmamıştır, ancak Osmanlılar bu yapıyı isimlendirmek için Irak kavramını (Hıtta-i Irakiye) kullanmış ve hem Osmanlıların hem Safevi ve İngiliz sefaretlerinin resmî yazışmalarında bu kavram görülmüsşür. ${ }^{10}$ Dolayısıyla, Irak'1 oluşturan bölgeler, Irak mandası kurulduğunda birbirinden tamamen bağımsız birimler değildi; aksine, aralarında nispeten yüksek derecede bir entegrasyon olan bir bölgeler topluluğuydu. Sözgelimi, tüm bunları özetleyecek biçimde, Mehmet Hurşîd Paşa'nın XIX. yüzyılın ortalarına ait Seyâhatnâme-i Hudûd'unda tam olarak şu ifadeler yer almaktadır:

"Fakat hafî olmaya ki bu ta'rîf Bağdâd eyâletinin şimdiki hududuna sâdık olup bu takdirce Bağdâd'in kürsîli hükûmeti olduğı Irak hıttası üç kısma münkasim olmuş olur. Zîrâ Irak kıt'ası tûlen Musul ile Abâdân ve arzan Kâdisiyye ve Hûlvân mâbeyninde kâ'in kut'a-i vesîadan kinâye olarak Basra ve Şehrizûr eyâletleri bu kıt'anın bir cüz-i mütemmimi olmaları ve idâre-i hâliyeye nazaran bunlar başka başka zikr olunmuş bulunmaları cihetle hâricde kalmış olduklarından îzâh-1 hâle mübâderet olunmuştur (vurgular bana ait)."11

$\mathrm{Bu}$ gelişime koşut olarak, XIX. yüzyıla gelindiğinde Iraklılık kimliği de farklı etnik ve dinî kökenlerden sınırlı sayıda aydın ve seçkin arasında bir kimlik boyutu haline gelmiş ve şiirlere, kitaplara, gazetelere ve derneklere konu olmuştur. ${ }^{12} \mathrm{XX}$. yüzyılın başında Arapça konuşulan coğrafyada

Nabil al-Tikriti, "Ottoman Iraq," The Journal of the Historical Society 7, no. 2 (2007): 209; Ismaeel Dawood, "Moats, Walls, and the Future of Iraqi National Identity," Istituto Affari Internazionali (2016): 7; Liora Lukitz, "Nationalism in Post-Imperial Iraq: The Complexities of Collective Identity," Critical Review 21, no. 1 (2009): 9-10; Visser, "Proto-Political Conceptions of Iraq in Late Ottoman Times," 144; Abdullah, Dictatorship, Imperialism and Chaos, 7.

10 Frederick F. Anscombe, "The Ottoman Empire in Recent International Politics - I: The Case of Kuwait," The International History Review 28, no. 3 (2006): 546; Visser, "Proto-Political Conceptions of Iraq in Late Ottoman Times," 145-147.

11 Mehmet Hurşî̀ Paşa, Seyâhatnâme-i Hudûd, çevrimyazı Alâattin Eser (İstanbul: Simurg Kitapçılık ve Yayıncılık, 1997), 49.

12 Phebe Marr, "One Iraq or Many: What Has Happened to Iraqi Identity," in Iraq Between Occupations: Perspectives from 1920 to the Present, eds. Amatzia Baram, Achim Rohde, and Ronen Reidel (New York: Palgrave Macmillan, 2010): 20; Visser, "Proto-Political Conceptions of Iraq in Late Ottoman Times," 147-152. 
milliyetçilik fikri yayılmaya başladığında, Irak topraklarında hem Arap birliğini hem de Irak'ın bağımsızlığını savunan seçkinler ortaya çıkmış ve farklı bölgelerden ve mezheplerden milliyetçiler arasında ağlar gelişmeye başlamıştır. ${ }^{13}$ Sözgelimi, Basra'nın önde gelenlerinden Seyid Talib, Sünni çoğunluktaki Bağdat ve Şii çoğunluktaki Basra'yı kastederek 1912'de Irak için bağımsızlık çağrısı yapmış ve bu çağrı üzerine Bağdat'taki genç milliyetçilerle temas kurmuştur. ${ }^{14}$ Öte yandan, bu dönemde Irakçılar ile panArapçılar arasında bir geçişkenlik olduğu ve her ikisinin de belirgin bir siyasî programa sahip olmadığg söylenebilir. Her halükârda Iraklılık, Irak mandası kurulduğunda birdenbire zuhur etmiş bir kimlik boyutu değildi; toplumun geniş kesimlerine ulaşmış olmasa da hem Sünniler hem Şiiler arasında ortak bir platform oluşturma potansiyeline sahip olan alternatif bir aidiyetti. Irak'1 oluşturan bölgeler arasındaki entegrasyonun da böylesi bir aidiyetin gelişebilmesi için asgarî temeli teşkil ettiği iddia edilebilir. Yine de Irak devletinin kurulmasından önce bir Irak milletinin varlığından söz etmek mümkün değildir, o vakte kadar en iyi ihtimalle bölgesel bir kimlikten söz edilebilir.

\section{Manda ve Kraliyet Döneminde Devlet Kimliği}

Irak, emperyalist aktörlerin müzakerelerinin sonucunda 1920'de düzenlenen San Remo Konferansı'nda ${ }^{15}$ bugünkü sınırlarıyla (Harita 1) resmî olarak ortaya çıkmıştır ve İngiliz hâkimiyetinde kalmıştır. Ancak aynı yılın yazında ülkede bir isyan dalgası yükselmiştir. Aslında, bu isyanın temeli sosyo-ekonomik sorunlarda yatmaktaydı ve geniş halk kesimleri arasında yeterince anlaşılamadığı için bir fikir olarak milliyetçiliğin bu isyanları başlatmaktaki rolü çok sınırlıydı. ${ }^{16}$ Ancak milliyetçilik, bu sosyo-ekono-

13 Abdullah, Dictatorship, Imperialism and Chaos, 10.

14 Dawisha, "National Identity and Sub-State Sectarian Loyalties in Iraq," 246. Bu bilginin Seyid Talib'e dair başka kaynaklarda yer almadığı not edilmelidir.

15 Yanlış biçimde, Irak'ın ortaya çıkışında Sykes-Picot Anlaşması'na sıklıkla atıf yapılmaktadır. Gelgelelim Irak'1 bugünkü haliyle somutlaştıran San Remo Konferansı'dır. Nitekim Sykes-Picot Anlaşması, Musul'u Fransa'ya, Bağdat'ı ve Basra'yı İngiltere'ye bırakmıştır. Dolayısıyla Sykes-Picot Anlaşması, bugünkü Irak'ın sınırlarına denk düşmemektedir.

16 Fanar Haddad, "The Terrorists of Today are the Heroes of Tomorrow: The Anti-British and anti-American Insurgencies in Iraqi History," Small Wars \& Insurgencies 19, no. 4 (2008): 455-463. 
mik isyanları ideolojik bir yöne de çevirmiştir ve isyanlar sırasında Irak'ın bağımsızlığını talep eden sesler yükselmiştir. Vatanseverlik ve milliyetçilik kavramları, toplumsal çoğunluğun belirgin bir kavrayışı söz konusu olmasa bile isyan sloganlarının önemli bir parçası haline gelmiştir. ${ }^{17}$ Aynı zamanda, toplumdaki kriz birlikteliği, Sünnilerin ve Şiilerin ileri gelenlerini defalarca bir araya getirmiş ve iki topluluğun toplandığ ritüeller (mesela, Hz. Hüseyin'i anma günleri) de sık sık dayanışma çağrılarına ve siyasî gösterilere dönüşmüştür. ${ }^{18}$ Dolayısıyla 1920 isyanları, milliyetçi bir çıkış noktasına sahip değildir, ancak Arap milliyetçiliğinin yanında ve mezhepçiliğin ötesinde Iraklılığın toplumsal ve siyasî anlamda kuruluşunda önemli bir sıçrama noktası olmuştur.

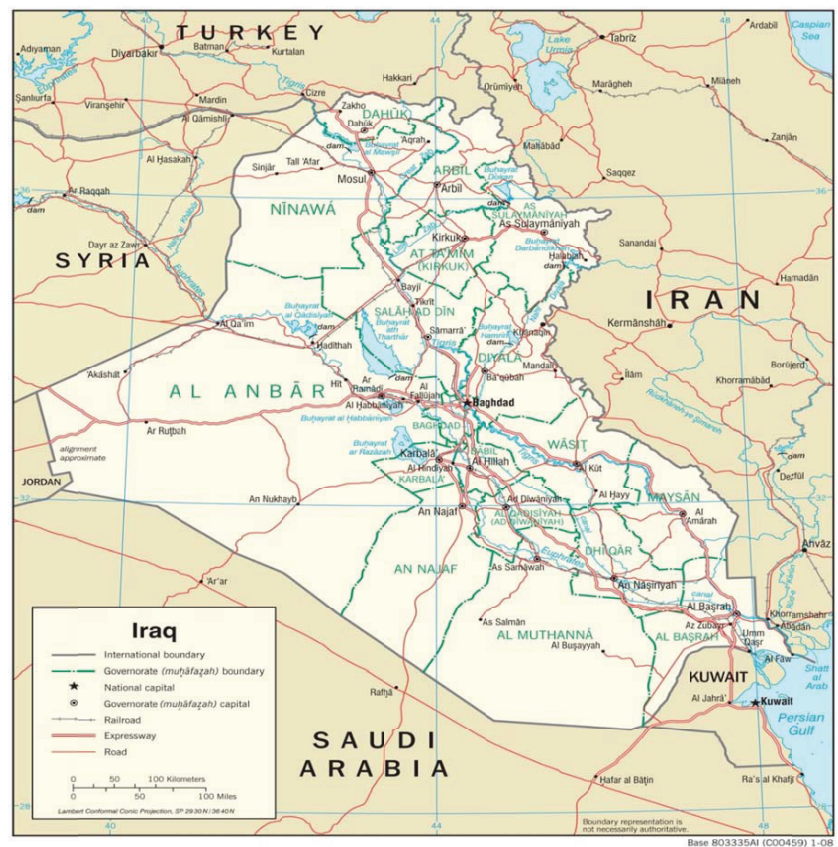

Harita 1. Irak haritası. ${ }^{19}$

17 Sami Zubaida, "The Fragments Imagine the Nation: The Case of Iraq," International Journal of Middle East Studies 34, no. 2 (2002): 207.

18 Amal Vinogradov, "The 1920 Revolt in Iraq Reconsidered: The Role of Tribes in National Politics," International Journal of Middle East Studies 3, no. 2 (1972): 134137.

19 Central Intelligence Agency (CIA), Maps, https://www.cia.gov/library/publications/ resources/cia-maps-publications/Iraq.html. 
1921'de ise Şerif Hüseyin'in oğullarından Faysal'ın kral olarak atand1ğ1 Irak mandası, İngiltere hâkimiyeti altında resmen ilan edilmiştir. Bir yandan, siyasî yelpazedeki konumuna göre değişmeksizin ülkedeki birçok siyasî grubun ve ismin ortak teması, sömürge karşıtlığ 1 ve Irak'ın bağımsızlığ olmuştur. Nitekim ülkedeki bütün siyasî partilerin programlarında bu amaçlar yer almıştır. ${ }^{20}$ Diğer yandan, sömürge karşıtlığı ve bağımsızlık, ülkenin birleştirici tek teması olarak kalmamıştır. Sözgelimi, 1922'de Arap yarımadasında yer alan Sünni Necd bölgesinden Irak'taki Şii Necef kentine yapılan akınlar, Necef'i bu saldırılara karşı korumak için Sünni ve Şii seçkinleri bir araya getirmiştir; Bağdatlı ve Musullu Sünni liderler tarafından Necef'e destek mesajları yayımlanmış ve Neceflilerle yan yana savaşmak için fetvalar çıkarılmıştır. ${ }^{21}$ Sözlerin ötesinde somut adımlar üretmese bile, 1920 ayaklanmasıyla birlikte bu tarihî an da milliyetçiler tarafindan aynı milliyetten iki farklı mezhep topluluğunun millî kimliği öncelemesine ve teşvik etmesine hizmet edecek temellerden biri olarak görülmüştür. ${ }^{22}$ Mezhep hatlarındaki bu ön-millî dayanışma işaretlerine ${ }^{23}$ rağmen, aynı yıllarda etnik hatlarda durum farklıydı: Kuzeyde Şeyh Mahmud liderliğindeki Kürt hareketi, Irak sınırları içerisinde böylesi bir toplumsal bütünlüğe meydan okumaya devam etmekteydi ve Kürt bağımsızlığında 1srarcıydı. ${ }^{24}$ Aynı zamanda, çoğunlukla merkezîleşmeye (mesela, zorunlu askerlik ve vergi gibi uygulamalara) yönelik rahatsızlıklar nedeniyle aşiret isyanları da 1920 'lerin ve 1930'ların karakteristik istikrarsızlıklarındand1. ${ }^{25}$

20 Johan Franzen, "The Problem of Iraqi Nationalism," National Identities 13, no. 3 (2011): 223-224; Adeed Dawisha, "Democratic Attitudes and Practices in Iraq, 1921-1958," Middle East Journal 59, no. 1 (2005): 15-21; Abdullah, Dictatorship, Imperialism and Chaos, 15.

21 Adeed Dawisha, Iraq: A Political History from Independence to Occupation (Princeton and New York: Princeton University Press, 2009), 78-79.

22 Dawisha, "National Identity and Sub-State Sectarian Loyalties in Iraq," 247-248.

23 Yine de bu dayanışma işaretlerinin tüm toplumu kapsadığ 1 ve özellikle Şii aşiretlerin devletle ilişkilerinde bir sorun olmadığı düşünülmemelidir. Manda yönetiminin tesisinden itibaren farklı zamanlarda ve bölgelerde çoğunlukla sosyo-ekonomik sebeplerle birçok aşiret isyanı çıkmıştır.

24 Sherko Kirmanj, "The Clash of Identities in Iraq," in Iraq Between Occupations: Perspectives from 1920 to the Present, eds. Amatzia Baram, Achim Rohde, and Ronen Reidel (New York: Palgrave Macmillan, 2010): 44-45.

25 Bu isyanlara dair geniş bilgi için bakınız: Peter Sluglett, Britain in Iraq: Contriving King and Country (London and New York: I.B.Tauris, 2007); Dodge, Inventing Iraq, 101-156. 
Öte yandan, manda yönetimiyle birlikte ülkede millî kimliğin ve toplumsal bütünlüğün inşasına yönelik çabalara girişilmiştir. Aslına bakılırsa, ülkedeki ulus inşacılarının çoğunluğu, öncelikle Irak milliyetçisi olmaktan ziyade Satı el-Husri gibi Arap milliyetçileriydi ${ }^{26}$ ve Arap birliğini öncelemeyen hareketlere şüpheyle bakmaktaydılar; yine de Arap birliğine karşı çıkmadığı sürece bu iki ideolojik pozisyonunun birbirlerini tamamen dışlayıcı olduğunu düşünmemişlerdir. ${ }^{27} \mathrm{Bu}$ ulus girişimcilerinin başta Irak'ta, sonra Arap dünyasında birliği ve bütünlüğü amaçladığı söylenebilir: öncelikle Irak'ın sınırları içerisinde milliyetçi duyguları canlandırmak, vatanseverlik ve aidiyet bağlarını kuvvetlendirmek, Irak'taki çeşitli toplulukları bir potada eritmek ve Irak'1 Arap dünyasının Prusya'sı haline getirmek. ${ }^{28} \mathrm{Bu}$ ulus-inşası çabasında ilk bakışta Irakçı1ık olarak yorumlanabilecek unsurlar bulmak mümkündür. Sözgelimi, Irak vatandaşları, Irak toprakları üzerinde ikamet eden eski Osmanlı tebaaları olarak tanımlanmıştır. ${ }^{29}$ Benzer biçimde 1925 anayasası, ülkedeki tüm dilleri, rrkları ve mezhepleri kapsayıcı bir dile sahiptir ve bu anayasada Arapçanın resmi dil olarak kabul edilmesi haricinde Arap kelimesine hiçbir atıf yapılmamıştır. Hâlbuki Iraklılık ile Araplık arasındaki bağ, bu ulus-inşacılarınca sorgulanmamıştır, daha doğrusu verili kabul edilmiştir. ${ }^{30} \mathrm{Bu}$ çerçeve içerisinde Arap milliyetçileri, vatanseverliği Arap milliyetçiliğine entegre ederek bilhassa eğitim yoluyla Irak'a sadakati topluma doktrine etmeye çalışmışlardır. Mesela, Millî Eğitim Müdürü Satı el-Husri'nin 1922'de tarih öğretmenlerine gönderdiği bir yönerge, "tarih dersinin amacının öğrencilerin kalplerinde vatansever ve milliyetçi duyguları güçlendirmek" olduğunu ilan etmiştir. ${ }^{31} \mathrm{Bu}$ anlamda,

26 Arap milliyetçiliği ile Irak milliyetçiliği arasındaki ayrım, Arapça karş1lıklarından hareketle kavmiye-vataniye ayrımı olarak da kavramsallaştırılmaktadır. Kavmiye, Irak'a dair her programı en iyi ihtimalle Arap birliğine yönelik bir araç olarak görür, Arap birliğini önceler ve Irak milliyetçiliğini Arap milliyetçiliğine engel olarak görmediği sürece destekler. Vataniye ise bir basamaktan ziyade kendi başına bir amaç olarak Irak'a yaklaşır, Arap olmayanlara bakışına benzer biçimde Arap ailesine yönelik de pragmatik bir tavır takınır, Arap birliğinden ziyade Irak'ın iç meselelerine öncelik verir.

27 Franzen, "The Problem of Iraqi Nationalism," 220; Dawisha, "The Unraveling of Iraq," 220-222.

28 Dawisha, "The Unraveling of Iraq," 220-222.

29 Zubaida, "The Fragments Imagine the Nation," 213.

30 Baram, “A Case of Imported Identity,” 281-292.

31 William L. Cleveland, The Making of an Arab Nationalist: Ottomanism and Arabism in the Life and Thought of Sati' al-Husri (Princeton: Princeton University Press, 1971), 147. 
standart seküler eğitimin ülkede yaygınlaşması, farklı toplumsal kökenlerden toplulukları (bilhassa Şii kitleleri) devletin nüfuz alanına ve Irak milleti kavramına dâhil etme projesinin en önemli ayaklarından biriydi. ${ }^{32}$

Eğitimin yanında devletin merkezîleşmesi ve bürokratikleşmesi de (yani devletin toplumdaki nüfuzunun artışı) kimlik inşası sürecinin önemli bir parçası olmuştur. Toplumsal kesimlerin geleneksel etnik ve mezhepsel çerçevelerinden ayrılmaları ve bu geleneksel aidiyetlerden ziyade devletin bu topluluklar için en anlamlı ve faydalı mekanizma olduğunu kavramaları, sadece devletin işlerliğine güveni artırmakla mümkündü. ${ }^{33} \mathrm{Bu}$ anlamda Kral Faysal, devlet kapasitesini artırmak için bir yandan Şii müçtehitlerle müzakere ederek onların rızasını alıp Şiilerin merkezî devletle uyuşmazlıklarını sonlandırmaya çalışmıştır. ${ }^{34}$ Diğer taraftan, genişleyen devlet kapasitesi sayesinde iç huzursuzlukların askerî yollarla bastırılması mümkün hale gelmiş, her toprağa ulaşılabilmesini sağlayan altyapı çalışmaları yapılmış ve kamu projeleri sayesinde istihdam yaratılmıştır; böylece, hem daha fazla sayıda vatandaş maddî olarak devlete bağımlı hale gelmiş hem de statü ve gelir durumundaki değişimle vatandaşların devletle özdeşleşmesi gittikçe daha fazla mümkün olmuştur. ${ }^{35}$ Ancak tüm bunlar, genel tabloya bakıldığında hâlâ marjinal görülebilir, çünkü kentsel alanlarda devletin nüfuzu önemli oranda gelişmiş olsa da, bilhassa nüfusun çoğunluğunun yaşadığı kırsal alanlar için devletin kapasitesini artırabilmek hala çok zordu. Ayrıca, 1927'de Samarra' da ve Kazımiye'de çıkan ayaklanmalarda görülebileceği üzere, Şii aşiretler ile devlet arasındaki gerilim sürmekteydi. ${ }^{36}$

Aynı zamanda, Irak milliyetçiliğinin bir ideoloji olarak da geniş toplumsal kesimlere hâkim olduğu henüz söylenemez. Mesela, 1920'lerde "Irak milletine inancını" vurgulayan ve gelecek on yılların tarih kitaplarında "Arap ülküsüne inanmış ve vizyonunu her şeyden önce sağlam bir Irak ulus-devleti kurmaya odaklamış bir lider" şeklinde betimlenecek olan ${ }^{37}$

32 Liora Lukitz, Iraq: The Search for National Identity (London: Frank Cass, 1995), 94.

33 Marr, "One Iraq or Many," 22; Dawisha, "The Unraveling of Iraq," 222.

34 Zubaida, "The Fragments Imagine the Nation," 211-212.

35 Marr, "One Iraq or Many,” 21; Dawisha, "The Unraveling of Iraq,” 223-224.

36 Kirmanj, "The Clash of Identities in Iraq," 45.

37 Dawisha, "The Unraveling of Iraq," 220; Dawisha, "National Identity and Sub-State Sectarian Loyalties in Iraq," 248-249; Baram, "Mesopotamian Identity in Ba'thi Iraq," 449. 
Kral Faysal, 1930'ların başlarında yazdıklarında "hâlâ bir Irak halkının oluşmamasından ve tebaasının vatanseverliğe kayıtsızlığından” yakınmıştır. ${ }^{38}$ Bir Irak milleti oluşturma ideallerinin uzağında kalınsa da, ülkedeki İngiltere hâkimiyetinin oluşturduğu huzursuzluk ve bunun getirdiği maliyet, 1932'de resmî olarak bağımsızlığı getirmiştir. Ancak bağımsızlık, içerideki milliyetçi programın hızını kesmemiştir, aksine milliyetçi doktrinasyonu yoğunlaştırmıştır. Sözgelimi, 1933'te eğitim genel müdürlüğüne getirilen Şii kökenli Muhammed Fazıl el-Cemali idaresinde buna yönelik birçok adım atılmıştır: İlk ve orta okulların sayısı artırılmış, seküler milliyetçi ve yekpare bir müfredat çerçevesinde eğitim yapılandırılmış, standart eğitimin Şii kırsal alanlara yayılması sağlanmış, Şiilerin bu eğitim sistemine girişi kolaylaştırılmış, böylelikle Şiilerin de Irak ulus-devletine entegrasyon süreci hızlandırılmıştır. ${ }^{39}$

Aynı zamanda bağımsızlık, bir taraftan uluslararası anlamda bağımsızlığı tanınmış ilk Arap devleti olarak Irak'ın Arap dünyasına yönelik hırslı bir politika gütmesinin önünü açarken, diğer taraftan da Arap milliyetçileri ile Irak milliyetçileri arasında bir güç mücadelesini görünür kılmıştır. Bu güç mücadelesi sonucunda, ülkenin yönünün zorunlu olarak Arap dünyasına çevrilmesinden rahatsız olan ve iç sorunlara eğilmenin çok daha önemli olduğunu düşünen vataniye kampı, 1936'da bir askerî darbe ile başa geçmiştir. ${ }^{40}$ Yeni hükümet, ortak Arap çıkarlarındansa Irak'ın çıkarlarını pragmatik biçimde gerçekleştirmeye çalışmışır. Mesela, bir yandan panArapçıların aksine Filistin'deki Siyonistlerle müzakerelere girişmiş, diğer yandan ortak bir Arap davası olarak öne sürülen Filistin meselesinden Irak'1 uzak tutmaya çalışmıştır. ${ }^{41}$ Ayrıca, o zamana dek ihmal edilen, Arap olmayan komşularla ilişkileri geliştirmeye çalışarak Türkiye ve İran'la Sadabad Paktı içerisine girmiştir. Ancak Arap milliyetçilerinin baskısı, önce hükümeti politikalarını gözden geçirmeye itmiş, sonra ise suikastlar ve kü-

38 Hanna Batatu, The Old Social Classes and the Revolutionary Movements in Iraq: A Study of Iraq's Old Landed and Commercial Classes and its Communists, Ba'thists, and Free Officers (Princeton: Princeton University Press, 1978), 25-26.

39 Lukitz, Iraq: The Search for National Identity, 104-110; Dawisha, "National Identity and Sub-State Sectarian Loyalties in Iraq," 250.

40 Michael Eppel, "The Hikmat Sulayman-Bakir Sidqi Government in Iraq, 1936-37, and the Palestine Question," Middle Eastern Studies 24, no. 1 (1988): 26-27.

${ }^{41}$ Eppel, "The Hikmat Sulayman-Bakir Sidqi Government in Iraq," 28-38. 
çük saray darbeleriyle bu hükümeti ortadan kaldırmıştır. ${ }^{42}$ Fakat bu kez de, Arap milliyetçiliğini şiddetle savunan Kral Gazi'nin 1939'da gizemli bir kazada ölmesinden sonra tahta üç yaşındaki oğlu geçince, İngiltere yanlısı olan ve Arap milliyetçiliğine sempati duymayan kral naibi Abdelilah ülkeyi fiilen yönetmeye başlamıştır. Bu yönetime de 1941 'de başka bir askerî darbeyle Alman yanlısı Arap milliyetçileri el koymuştur; ancak İngiltere'nin askerî müdahalesiyle İngiltere yanlısı bir hükümet kurulmuştur. ${ }^{43}$

Bu müdahalenin ardından İngiltere, manda döneminde ihmal ettiği alanlar olan askeriyeyle ve eğitimle daha aktif biçimde meşgul olmuştur. Sözgelimi, müfredattan pan-Arapçı vurgular kaldırılmış ve Arap milliyetçisi öğretmenler kovularak yerlerine Batı'da eğitim görmüş ya da sol eğilimli öğretmenler getirilmiştir. ${ }^{44} \mathrm{Bu}$ dönem, aynı zamanda Irak topraklarının Mezopotamya içeriğinin işlendiği önemli bir zaman aralı̆̆ olmuştur. 1930'larda da eklektik biçimde kullanılan Mezopotamya-Irak bağlantılarına rastlamak mümkündü; ancak bilhassa 1940'lardan itibaren geçmişteki anlatının aksine, kadim Mezopotamya halkları ile Irak milleti arasında aynı toprağın farklı sakinleri olarak değil de bir devamlılık oluşturacak şekilde sistematik bağlantılar kurulmaya başlanmış, Mezopotamya medeniyetlerine dair müzeler ve enstitüler kurulmasına yönelik yatırımlar yapılmış, Irak'ın sahip olduğu mirası yücelten tarih kitapları ve tezleri üretilmiş, II. Faysal 1953 'te tahta geçtiğinde ise Irak-Mezopotamya bağlantısı resmî olarak benimsenmiştir. ${ }^{45}$ Aslında, Irak'ın (ve Iraklıkların) altın çağı olarak Mezopotamya'nın yüceltilmesi, sadece pan-Arapçı vurguların azaltılması açısından değil, Abbasiler dönemini yücelten eski teze nazaran Şiiler aç1sından da daha işlevsel görülmüştür. ${ }^{46}$

$\mathrm{Bu}$ dönem, Iraklılık kimliğinin yayılımı açısından doğrudan doktrinasyan dışında da Irak'ın en önemli tarihî dönemlerinden biriydi: Artan parti sayısında görüldüğü gibi siyasî atmosfere çoğulculuk hâkim olmuş (yani birçok kesimden Iraklının ortak platformlarda buluşulabilmesi mümkün olmuş), Şiilerin ve Kürtlerin yönetimde ve bürokraside temsil oranları art-

42 Kirmanj, "The Clash of Identities in Iraq," 46; Tripp, A History of Iraq, 86-97.

43 Kirmanj, "The Clash of Identities in Iraq," 46.

44 Reeva S. Simon, "The Teaching of History in Iraq before the Rashid Ali Coup of 1941," Middle Eastern Studies 22, no. 1 (1986): 48-49.

45 Baram, “A Case of Imported Identity,” 292-298.

46 Baram, “A Case of Imported Identity,” 298. 
mış (böylece bu kesimlerin devletle aralarındaki mesafe azalmış), devlete bağımlı ve eğitimli orta sınıf genişlemiş (bu da geleneksel aidiyetlerden ziyade devlete sadakati güçlendiren bir etken olmuş), Bağdat Paktı'nda görülebileceği üzere devletin rotası Arap dünyasından ziyade Arap olmayan ülkelere ve Batı'ya çevrilmiş ve böylece dış politikada "önce Irak" politikası izlenmiştir. ${ }^{47}$ Diğer taraftan, bu çoğulcu ortama ideolojik açıdan hâlâ kavmiye ve vataniye kamplarının egemen olduğu söylenebilir. Arap milliyetçiliğini savunan Baas Partisi ve İstiklal Partisi ile vataniye kampındaki Irak Komünist Partisi ve Millî Demokratik Parti, siyasî arenada ve toplumda hâkim olan esas partilerdi. ${ }^{48}$ Her ne kadar bu kesimlerin siyasî programlarında önemli farklılıklar olsa da, özellikle hükümetin Batı yanl1lığına ve baskısına muhalefette buluşmaları, 1958'de Hür Subaylar darbesini ve kraliyetin lağvedilip cumhuriyetin ilanını getirmiştir.

\section{Cumhuriyet Döneminde Devlet Kimliği}

Darbeyle başa gelen Hür Subaylar'ın vataniye (başta darbe lideri Abdülkerim Kasım ve Komünistler) ve kavmiye (Abdüsselam Arif ve Baas Partisi) kampları arasındaki güç mücadelesi, öncelikle vataniye saflarının ve Abdülkerim Kasım'ın kontrolüyle neticelenmiştir. ${ }^{49}$ Kasım rejiminin temel önceliği iç meseleler olmuştur; zaten bu döneme tecrit dönemi de denilmektedir. Rejim, toplumsal bütünlüğe yönelik bir adım olarak aşiret yasalarını iptal ederek ve toprak reformunu uygulayarak aşiretlerin ve aşiret reislerinin etkisini azaltmıştır. ${ }^{50} \mathrm{Bu}$ uygulamada, devlet ile halk arasındaki aracılardan biri olan aşiretlerin etkisinin azaltılması ve devlet-toplum ilişkisinin daha doğrudan bir hale getirilmesi amaçlanmıştır. Diğer taraftan Kasım, ülkedeki ve bölgedeki pan-Arapçı rüzgârdan Irak'ı uzak tutmak ve Irak millî kimliğini güçlendirmek için "bin yıllık Irak kültürü” üzerine eğilmiştir; sözgelimi, kadim Mezopotamya medeniyetlerinden Akadların güneş tanrısını devrimin sembolü yapmış ve Sümer mitolojisinden İştar

\footnotetext{
47 Marr, "One Iraq or Many," 23.

48 Kirmanj, "The Clash of Identities in Iraq," 47.

49 Franzen, "The Problem of Iraqi Nationalism," 225-226; Tripp, A History of Iraq, 144157.

50 Jacqueline S. Ismael and Shereen T. Ismael, "Iraqi Women under Occupation: From Tribalism to Neo-Feudalism," International Journal of Contemporary Iraqi Studies 1, no. 2 (2007): 252.
} 
yıldızını Irak bayrağına entegre etmiştir. ${ }^{51}$ İlaveten, Danışma Bakanlığı'nı kurup buraya Irakçı eğilimleriyle bilinen isimleri atamıştır. ${ }^{52}$ Ancak bu yönetim, aynı zamanda, meclis ve siyasî partiler gibi sivil kurumları zayıflatarak halkı devletten uzaklaştırmıştır. ${ }^{53}$

Öte yandan, kavmiye-vataniye mücadelesi, 1963 ’te önce Baasçı subayların Kasım'ı devirdiği askerî darbeyi, ardından da Arif grubunun Baasçıları devirdiği saray darbesini getirmiştir. Arap birliğine dair herhangi bir somut gelişme vücut bulamasa da, bu darbeden 1967'ye kadar Irak'ın rotası neredeyse tamamen Arap dünyasına çevrilmiştir. ${ }^{54} \mathrm{Kasım}$ rejiminin getirdiği Araplık öncesi semboller, “Arap ruhunu yansıtmadığı” ve "toprağın tarihi ile halkın tarihi farklı olduğu” için, Kasım'ın düşüşünden sonra aşamalı olarak kaldırılmıştır. ${ }^{55}$ Diğer taraftan, ülke seçkinleri arasındaki güç mücadelesi, 1968'de Baas iktidarını bu kez çok daha uzun soluklu olacak biçimde geri getirmiştir. Baas dönemi, Iraklılık kimliği için uzun ve kritik bir dönem teşkil etmiştir.

Aslında Baas Partisi, 1967'deki Arap-İsrail Savaşı'nın pan-Arapçı ideolojinin meşruiyetini önemli oranda aşındırdığı bir ortamda iktidara geldiğinde öncelikle pan-Arapçılığın geçerliliğini ispatlama baskısını hissetmiştir. ${ }^{56}$ Parti, "Filistin'e özgürlük ve bütün Arap dünyasında milliyetçi devrim" ayakları üzerinde devrimci bir pan-Arapçı çizgiyi öne çıkartmıştır. Söylem düzeyinde hem Mısır'daki Nasır yönetimini hem Suriye'deki Baas rejimini açıkça eleştirmiş, Arap dünyasını silahlı halk mücadelesine davet etmiş ve Filistin konusunda reddiyeci bir tavır takınmıştır. ${ }^{57}$ Ancak Parti'nin kurulu olduğu bu pan-Arapçı politika, 1960'ların sonlarından itibaren birkaç fark11 gelişmeden dolayı yerini vataniye politikasına bırakmaya başlamıştır: 1969'da İran ile Irak arasında patlak veren sinır sorununun ortak Arap sorunlarından ziyade Irak'ın sorunlarına dönmeye yönelik baskısı, kuzeyde

\footnotetext{
51 Donald Malcolm Reid, "The Postage Stamp: A Window on Saddam Hussein's Iraq," Middle East Journal 47, no. 1 (1993): 84.

52 Franzen, "The Problem of Iraqi Nationalism," 226.

53 Marr, "One Iraq or Many," 24.

54 Marion Farouk-Sluglett and Peter Sluglett, Iraq since 1958: From Revolution to Dictatorship (London and New York: I.B.Tauris, 2001), 94-95.

55 Reid, "The Postage Stamp," 84; Baram, "A Case of Imported Identity,” 301-302.

56 Baram, Culture, History and Ideology in the Formation of Ba 'thist Iraq, 13-14.

57 Farouk-Sluglett and Sluglett, Iraq since 1958, 132-134.
} 
fiilî olarak özerk bir hareket sahası oluşturan Kürtleri Irak'a entegre etme amacı, pan-Arapçı1lı̆̆ Sünnicilikle eş tutan ya da soyut bir ideoloji olarak gören geniş Şii kitlelerle ilişkileri somut vataniye çizgisinde iyileştirme çabas1, Baas Partisi içerisinde bir güç mücadelesi sonucu ortaya çıkan Suriye gerilimini Iraklılık kimliği üzerinden meşrulaştırma isteği, Nasır'ın Arap dünyasındaki popüler nüfuzunu geriletme gayesi, 1950'lerden beri Arap birliğine yönelik girişimlerin pratik anlamdaki başarısızlığ ve 1970'lerin başlarında karşılaşılan ekonomik problemler. ${ }^{58}$
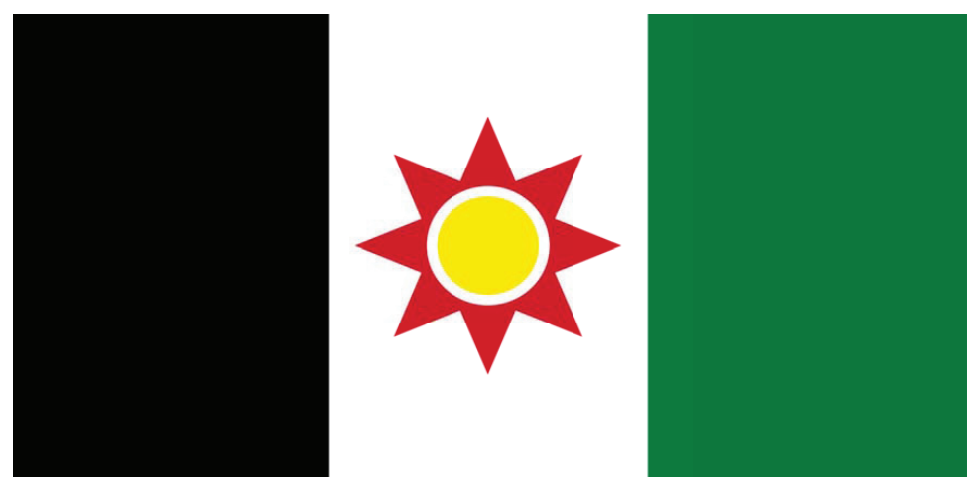

Görsel 1. 1959-1963 döneminde kullanılan Irak bayrağı. ${ }^{59}$

1974'te yapılan Sekizinci Bölgesel Kongre'nin önergesinde belirtildiği üzere, mevcut Arap rejimlerine karşı takınılan sert tutum, Irak'ın üzerinde gerçekten de önemli bir yük oluşturmuştur. ${ }^{60} \mathrm{Bu}$ bağlamda Arap dünyasından geri çekilişin dışarıdaki izleri, Irak'1n 1971'de Ürdün'de konuşlu birliklerini çekerek Filistin meselesiyle meşguliyetini azaltmasında, Mısır'ın İsrail'e karş1 yumuşayan politikalarına dair eleştiri tonunun düşmesinde ve 1974’te Gazze Şeridi ile Batı Şeria'da küçük bir Filistin devletinin kurulmasını kabul etmesinde görülebilir. ${ }^{61}$ İçerideki izleri ise çok daha detaylı

\footnotetext{
58 Baram, Culture, History and Ideology in the Formation of Ba thist Iraq, 14-17.

59 "The Evolution of the Iraqi Flag," Al Arabiya English, May 26, 2015, http://english. alarabiya.net/en/perspective/infographics/2015/05/26/The-evolution-of-the-Iraqiflag-.html.

60 Baram, "Qawmiyya and Wataniyya in Ba'thi Iraq," 193.

${ }^{61}$ Baram, "Qawmiyya and Wataniyya in Ba'thi Iraq," 194-195.
} 
bir ulus-inşası ve tarih-merkezli bir millî-topraksal bilinç geliştirme projesiydi. Aslına bakı1ırsa Parti, iktidara geldikten birkaç ay sonra (yani siyasî anlamda pan-Arapçı çizgisini sürdürürken dahi) kültürel anlamda Irak'ın Araplık ve İslam öncesi tarihine aşağıda örneklendirilen biçimde ilgi göstermeye başlamıştır, ancak parti içi ve bölgesel eleştirilerden kaçınmak için bu ilgiyi siyasî olarak öne çıkarmamaya dikkat etmiştir. ${ }^{62}$

Bu anlamda Parti'nin kimlik anlayışının özellikle 1970'ler boyunca üç ana ayağı vardı: Irak'1 kimlik meselesinin ana odağı yapmak, Irak'ın kadim ve modern tarihine yaslanmak ve Irak'in Arap dünyasındaki potansiyel liderlik rolünü vurgulamak. ${ }^{63}$ Öncelikle, bu Irak merkezli eğilim, Saddam Hüseyin'in konuşmalarından bazı ifadelerle örneklendirilebilir: "Arap milletinden bahsederken Irak halkını unutmamalıyı"; "Arap vatanından bahsederken, Iraklıları yaşadıkları toprakların gururunu hissetmeleri için eğitmeyi ihmal etmemeliyiz"; "Irak milleti Araplardan ve Arap olmayanlardan oluşur"; "Arap vatanından bahsederken, Arap olmayan vatandaşlarımızı Irak dışında bir vatan aramaya zorlamamalıyız"; "Kürt özerkliğini tartışmaktan kaçınamayız, ancak bu özerkliğin Araplar ve Kürtler arasında bir Çin Seddi örmesine izin vermemeliyiz"; 64 "Arap, Kürt ya da Türkmen kültüründen bahsedilmemelidir, her biri Irak kültürü olarak ele alınmal1dır"; 'Şii ya da Kürt demek yerine Basralı ya da Süleymaniyeli demeliyiz"; "Haydi Arap ve Kürt kelimelerini silelim ve bunları Irak milleti kavramıyla değiştirelim". ${ }^{65}$ Böylesi bir ideolojik formülasyon için ülkenin maddî şartları da hazırdı. Nitekim 1972 'de petrol endüstrisinin millîleştirilmesiyle ve 1973 'te petrol fiyatlarının yükselmesiyle kapasitesi ciddi oranda artan devletin yaptığı iç yatırımlar sonucunda rejimin ana direği olan orta sınıfın görülmedik derecede genişlemesinin mezhep ve aşiret kimlikleri gibi geleneksel kimliklerin aşınması sürecini hızlandırdığı söylenebilir. ${ }^{66}$

62 Baram, "Territorial Nationalism in the Middle East," 425.

63 Baram, Culture, History and Ideology in the Formation of Ba thist Iraq, 13-18.

64 Bu noktada, rejimin 1970’te Kürt meselesini nihayete erdirmek için özerk Kürt bölgesini tanıdığı ve Kürt kimliğini meşru kabul ettiği, ancak özerklik müzakerelerinin 1974 'te yeniden silahlı çatışmaya evrildiği belirtilmelidir.

65 Baram, "Qawmiyya and Wataniyya in Ba'thi Iraq," 196; Baram, Culture, History and Ideology in the Formation of Ba thist Iraq, 34-35.

66 Hala Fattah and Frank Caso, A Brief History of Iraq (New York: Infobase Publishing, 2009), 212-213; Farouk-Sluglett and Sluglett, Iraq since 1958, 173. 


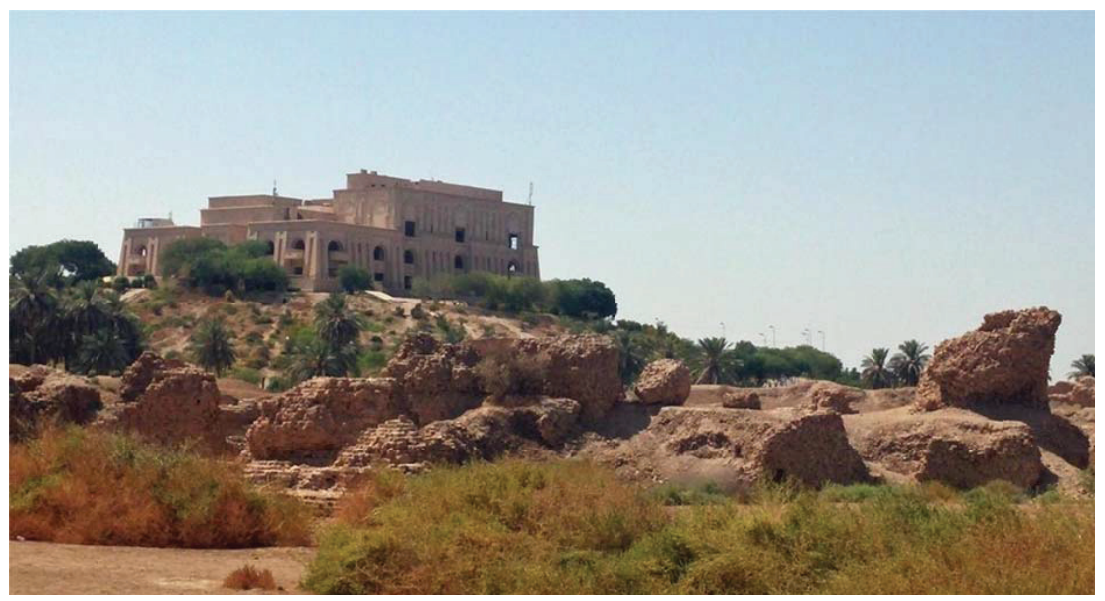

\section{Görsel 2. Sümer tapınağı Ziggurat biçiminde inşa edilen, Saddam Hüseyin'in başkanlık sarayı. ${ }^{67}$}

Irak-temelli bu kimlik formülünün doktriner anlamda merkezinde ise Mezopotamya miti vardı: kadim Mezopotamya'nın genetik ve kültürel mirası olarak Irak'1 öne çıkarmak. Bu anlayışa göre Sümer ve Akad krallıkları, Irak vatanının birliğinin ilk ifadesini sunmuşlardır. ${ }^{68}$ Antik Mezopotamya'nın Iraklılığa topyekûn biçimde entegre edilişi, rejimin ulus-inşa projesinin temelini teşkil etmiştir. Bu projeyle, modern Irak ile kadim Mezopotamya arasındaki devamlılığı vurgulayarak Iraklıların kendilerini Mezopotamya halklarının etnik torunları ve kültürel mirasçıları olarak görmesi, bu geçmişleriyle gurur duyması, böylece Iraklılar için Sünni-Şii ve Arap-Kürt ayrımlarını aşan ortak bir tarihin oluşturulması ve Mezopotamya mirasının Arap ailesi içerisinde Irak'ın üstünlüğünü ve emsalsizliğini göstermesi amaçlanmıştır. ${ }^{69} \mathrm{Bu}$ Mezopotamya teması, rejimin düşüşüne kadar devam eden pan-Arapçı söylemlerde görülebileceği üzere Baas döneminin tek kimlik vurgusu değildi. Nitekim Saddam Hüseyin, pan-Arapçı temaları da

67 Paul Cooper, "Saddam's 'Disney for a Despot': How Dictators Exploit Ruins," $B B C$, April 20, 2018, http://www.bbc.com/culture/story/20180419-saddam-disney-for-adespot-how-dictators-exploit-ruins.

68 Baram, Culture, History and Ideology in the Formation of Ba'thist Iraq, 49.

69 Benjamin Isakhan, "Targeting the Symbolic Dimension of Baathist Iraq: Cultural Destruction, Historical Memory, and National Identity," Middle East Journal of Culture and Communication 4 (2011): 260-265. 
konuşmalarında vurgulamaya hayatı boyunca devam etmiştir. Ancak Mezopotamya teması, Araplıktan ziyade Iraklılığ vurguladığı için ve Iraklılık kimliğinin inşasına katkıda bulunacağı düşünülerek rejim tarafından bilhassa desteklendiği için önem arz etmektedir. ${ }^{70}$

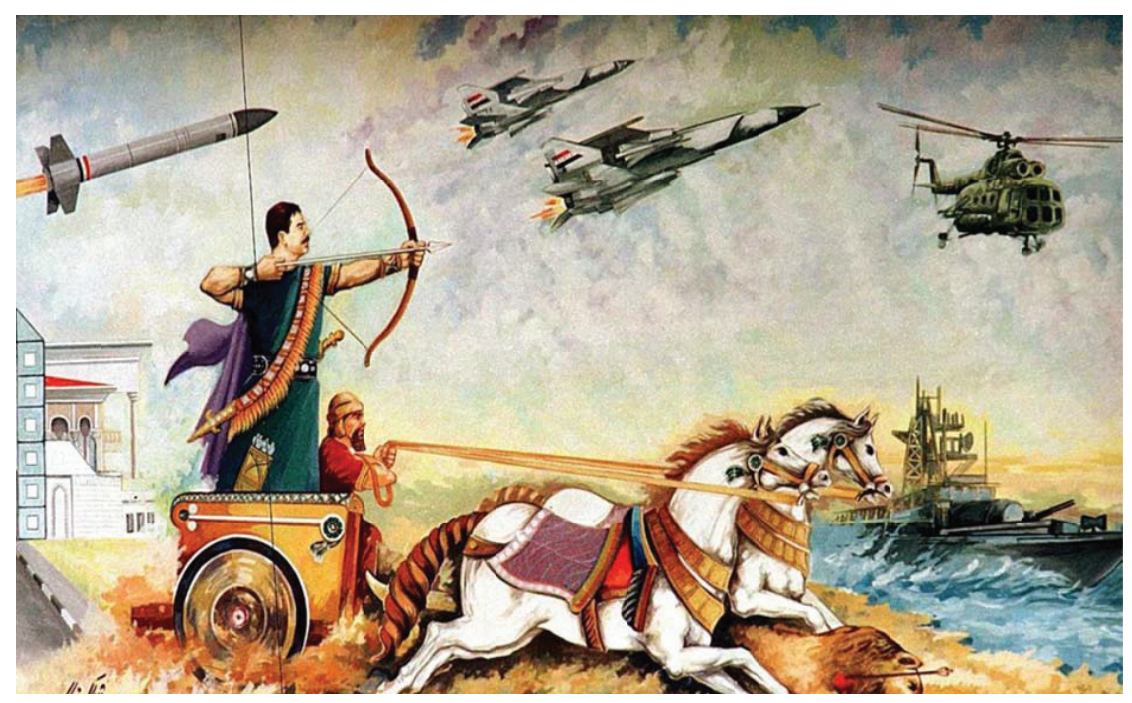

Görsel 3. Kadim ve modern zamanlar arasında varsayılan bağlantıları vurgulayan bir propaganda afişi. ${ }^{71}$

Bu kültürel kampanya kapsamında kadim sembolleri toplumsal ve siyasî hayatın birçok farklı yerinde görmek mümkün olmuştur: Irak kültürü ile Sümer kültürü arasındaki devamlılığ vurgulayan kadim folklorik unsurlar keşfedilmiş ya da icat edilmiştir; kadim sanatlar ve sanat ürünleri canlandırılmıştır; arkeolojik araştırmalara ciddi bütçeler ayrılmıştır; müzelerin kapasitesi ve sayısı artırılmış, bilhassa çocukların bu alanları ziyaret etmesi sağlanmıştır; Hatra ve Ninova'nın yanı sıra Iraklılık kimliğinin odak noktası olarak görülen Babil şehri en az 100 milyon dolarlık bir maliyetle 1987-1988'de restore edilmiştir (ki Iraklılara "Nebukednezar'ın torunları" şeklinde hitap edilmekteydi); Irak ile Mezopotamya arasındaki devamlılık

70 Baram, "Mesopotamian Identity in Ba'thi Iraq," 435; Baram, "A Case of Imported Identity," 304.

71 Cooper, "Saddam's 'Disney for a Despot': How Dictators Exploit Ruins." 
vurgulanarak bu restorasyona Irak medyasında özel önem verilmiştir; Mezopotamya temalı birçok oyun, film ve medya içeriği üretilmiş, konuyla alakalı makaleler ve şiirler teşvik edilmiştir; resmigeçitler Mezopotamya sembolleriyle donatılmıştır; Irak'tan kaçırılmış antik eserlerin Irak'a getirilmesi için büyük bir diplomatik kampanya başlatılmıştır; kadim Mezopotamya ritüelleri modern festivaller biçiminde canlandırılmıştır; Babil ve Ninova gibi kadim Mezopotamya isimleri Irak'ın idarî haritasına eklenmiştir; Saddam Hüseyin'in antik temalarla donatıldığ 1 (mesela, Babil kralı Nebukednezar ile boy gösterdiği) propaganda afişleri üretilmiştir. ${ }^{72}$

Öte yandan, 1980'de başlayan İran-Irak Savaşı dönemi, Baas rejiminin Araplığı fazlaca vurguladığı bir dönem olarak öne çıkarılmaktadır. Gerçekten de Irak Şiilerinin İran'ın dinî çağrılarına kapılmasını önlemek için Araplık ile Perslik arasındaki farklar bu dönemde özellikle öne çıkarılmıştır. Sözgelimi, 637'de Araplarla Sasaniler arasında yapılan Kadisiye Savaş1, rejimin bir propaganda malzemesi haline getirilmiş ve Hz. Ali'nin ve Hz. Hüseyin'in Araplığı üzerinde durulmuştur. ${ }^{73}$ Diğer taraftan, İran-Irak Savaşı, vataniye fikrinin de vurgulandığı zirve noktalardandı. Dönemin propaganda kampanyalarında Irak'ın birliği ve bütünlüğü ve "değerlerini ve ruhunu korumak için savaşan bütün bir Irak milleti" teması vard1. ${ }^{74} \mathrm{Bu}$ arada, savaş boyunca güneyde Şiilerin büyük kısmı ve kuzeyde oluşturulan Kürt gayri nizami birlikleri rejimin tarafinda yer almıştır; böylece savaş, Irakl1lık kimliğinin bir anlamda zaferi olarak görülmüştür. ${ }^{75}$ Fakat devletin kapasitesini önemli oranda aşındırdığı için aynı zamanda bu kimlik için bir gerilemenin de başlangıcı olmuştur. Diğer yandan, 1982'de bile üst düzey bir Baas yetkilisi, "ayrılıkçılığın, mezhepçiliğin ve aşiretçiliğin toplumun birliğini parçaladığından" (yani devlet-altı ve devlet-üstü kimliklerin devlet kimliğine üstün gelmesinden) yakınmaktaydı. ${ }^{76}$

72 Kamyar Abdi, "From Pan-Arabism to Saddam Hussein's Cult of Personality: Ancient Mesopotamia and Iraqi National Ideology," Journal of Social Archaeology 8, no. 1 (2008): 21-28; Franzen, "The Problem of Iraqi Nationalism," 228; Baram, "A Case of Imported Identity," 302-303; Baram, "Mesopotamian Identity in Ba'thi Iraq," 427435; Baram, "Territorial Nationalism in the Middle East," 425.

73 Isakhan, "Targeting the Symbolic Dimension of Baathist Iraq," 263.

74 Isakhan, "Targeting the Symbolic Dimension of Baathist Iraq," 263-264.

75 Martin van Bruinessen, "The Kurds between Iran and Iraq," MERIP Middle East Report 141 (1986): 18; Marr, "One Iraq or Many," 28; Dawisha, "National Identity and Sub-State Sectarian Loyalties in Iraq," 252.

76 Dawisha, "Identity and Political Survival in Saddam's Iraq," 554. 
1990'l yıllar ise devletin kurumsal ve ideolojik olarak yıkıldı ğı bir dönemdi. 1980-1988 İran-Irak Savaşı'nı Kuveyt'i işgal ederek telafi etmeye çalışan Baas rejiminin uluslararası koalisyon tarafindan 1991'de Kuveyt'ten sürülmesiyle (ve bu şekilde maddî anlamda zayıflamasıyla) güneyde Şiiler arasında ve kuzeyde Kürtler arasında isyan dalgası baş göstermiştir. ${ }^{77}$ Rejim, her iki bölgede de şiddet kullanarak isyan dalgasını kırsa da, bir taraftan Birleşmiş Milletler kararıyla güvenli bölge şeklinde oluşturulan ama fiilî olarak Kürt yönetimi anlamına gelen Kürt bölgesiyle yan yana olmak zorunda kalmıştır. Diğer taraftan da devletin maddî gücünü önemli oranda aşındırıp Iraklılık kimliğinin yaslandığı ana direk olan orta sınıf ile rejim arasındaki ilişkiyi yok eden uluslararası yaptırımlarla baş başa kalmıştır. ${ }^{78} \mathrm{Bu}$ ortamda rejim, iç güvenliğini tesis etmek için patronaj sistemini s1kılaştırmış, Sünni aşiretlerin otoritesini resmî olarak pekiştirmiş, aşiret aidiyetlerini ve kültürünü teşvik etmiş ve böylece daralmakta olan toplumsal tabanını daha da daraltmıştır. ${ }^{79}$ Netice itibarıyla, Saddam Hüseyin'in 1990'larda aşiretçiliği kurumsallaştırmaya yönelik hareket ettiği söylenebilir ki bu da yaklaşık yetmiş yıldır sürdürülen millî bir konsensus yaratma girişiminin tam tersiydi.

\section{2003 İşgali Sonrasında Iraklılık}

Amerikan işgali, bu kaotik bağlamda önemli bir kırılma noktası olmuştur. "Haydut devlet" olarak tanımladığı Irak'ta Amerikan yanlısı bir rejim inşa etmeyi, kalıcı askerî üsler kurmayı ve Irak'ın petrol arzını kontrol ve güvence altına alıp petrol piyasasına baskı yapmay1 ${ }^{80}$ amaçlayan Amerikan işgali, Saddam Hüseyin'in Baas rejimini devirmiş ve rejimin nispeten işleyen son dayanakları olan güvenlik aygıtını ilga etmiştir. Böylece, Irak'ta muazzam büyüklükte bir güç boşluğu oluşmuştur. İşgalin ardından Temmuz ayında kurulan Geçici Koalisyon Yönetimi, on üç Şii, beş Sünni, beş Kürt, bir Türkmen ve bir Asuri üyeden oluşturulmuş ve böylece bir yandan

77 Tripp, A History of Iraq, 244-258.

78 Toby Dodge, "Iraqi Transitions: From Regime Change to State Collapse," Third World Quarterly 26, no. 4-5 (2005): 706-709.

79 Tripp, A History of Iraq, 259-267; Dawisha, "Identity and Political Survival in Saddam's Iraq," 562-567.

80 Doug Stokes, "The War Gamble: Understanding US Interests in Iraq," Globalizations 6, no. 1 (2009): 107-112. 
Irak toplumunun ABD tarafindan nasıl algılandığını yansıtmış olup diğer yandan da devlet-altı kimliklerin kurumsallaşmasında önemli bir aşama teşkil etmiştir. ${ }^{81}$ Her halükârda, 2003 işgaliyle Irakl1lık kimliğinden neredeyse söz edilmez olmuştur. Gerçekten de etnik ve mezhepsel kamplaşma, toplumsal ve siyasî hayata şiddetli biçimde nüfuz etmiştir.

$\mathrm{Bu}$ ortamda ülkedeki devlet-altı kimlik gruplarının ulusal bütünle tezat teşkil edecek biçimde ayrı gündemleri oluşmuştur. Saddam Hüseyin döneminde ülkenin yönetici seçkinleri olan ve özellikle 1990'larda aşiret bağları üzerinden sıklıkla kayırılan Sünni Araplar, şimdi kendilerini radikal bir konumda bulmuş ve ülkedeki direnişçi etkinliğin toplumsal temelini teşkil etmişlerdir. Bilhassa 1980'lerden itibaren İran'dan etkilendiklerine veya etkilenebileceklerine dair şüphelerle marjinalleştirilen Şii Araplar, bir taraftan ülkenin yönetimi için bir iç mücadeleye girişmiş, diğer taraftan da Mukteda el-Sadr gibi isimlerin ardında direnişe katılmışlardır. Irak'ın kuruluşundan beri farklı zaman aralıklarında ayrılıkçı ya da özerklik yanlısı bir gündemi öne çıkarmış olan Kürt siyasî hareketi de Amerikan işgalini firsat olarak değerlendirip koalisyon güçleriyle birlik olmuş ve neticede Irak Kürdistan Bölgesel Yönetimi'nin resmiyet kazanmasıyla anayasal özerklik elde etmiştir. ${ }^{82}$ Siyasî parçalılık, Irak’1 oluşturan sadece bu üç büyük toplumsal grup açısından değil, Türkmenler gibi daha küçük gruplara bakıldığında dahi gözlemlenebilmiştir. ${ }^{83}$

2005 ulusal seçimleri de Iraklılık kimliğinin geri çekilişine dair ciddi işaretler vermiştir, nitekim Irak milliyetçisi İyad Allavi'nin 275 sandalyeden 25 'ini kazanabilmesine karşı1ık, mezhepçi ve etnik milliyetçi partilerin öne çıkışı tartışmasızdı. ${ }^{84}$ Sünnilerin en az yüzde 75 'i Sünni liderlerin çağrısına

81 Dodge, "Iraqi Transitions," 715.

82 İşgal sonrası siyasî manzaranın kuramsal literatür içerisinde tartışıldığı önemli bir çalışma olarak bakınız: Fanar Haddad, "Sectarian Relations in Arab Iraq: Contextualising the Civil War of 2006-2007," British Journal of Middle Eastern Studies 40, no. 2 (2013): 115-138.

83 Bu gruplardan biri olan Türkmenler arasındaki mezhep çatışması için bakınız: Tunahan Yıldız, "Mezhep Çatışmasına Bir Etnik Grup ve Yerel Bağlam Üzerinden Bakmak: Irak Türkmenleri ve Telafer Örneği," Türkiye Ortadoğu Çalışmaları Dergisi 4, no. 2 (2017): 41-73. Benzer biçimde, 2003 işgalinden sonra yoğunlaşan Kürt-Türkmen rekabeti için bakınız: Tunahan Yıldız, "Modern Irak’ta Kürt-Türkmen İlişkileri," Avrasya Etüdleri 54, no. 2 (2018): 105-115.

84 "Shia Alliance Wins Iraq Elections," The Guardian, January 20, 2006, https://www. theguardian.com/world/2006/jan/20/iraq. 
uyarak seçimleri boykot etmiş, Kürtlerin yaklaşık yüzde 95'i Kürdistan İttifakı'nı desteklemiş, Şiilerin yaklaşık yüzde 75'i Birleşik Irak İttifakı'na oy vermiştir. ${ }^{85}$ Dolayısıyla 2005 seçimleri, ulusal çaplı bir devlet-altı kimlik referandumu rolü oynamıştır. Ülkede oluşan güç boşluğu ve devlet zayıflığı içerisinde devlet-altı gruplar, kendi siyasî ajandalarını oluşturmuşlardır. Bu ortamda, bir yandan Kürdistan Bölgesel Yönetimi'nin özerkliği resmîleşirken ve sağlamlaşırken, tarihsel olarak özerklik gündemi olmayan Şiiler arasında Abdulaziz el-Hekim gibi bazı yeni seçkinler de artık Şii vilayetlerin özerkliğini açıkça tartışmaya başlamışlardır. ${ }^{86} \mathrm{Bu}$ arada, Samarra'da bulunan el-Askeri türbesinin Şubat 2006'da el-Kaide tarafından bombalanmasıyla 2008'e kadar yoğun biçimde sürecek olan bir mezhepçi şiddet süreci başlamıştır. Bu şartlar altında Irak'ı birleşik bir ülke ve toplum olarak görmek gittikçe zorlaşmıştır.

Yine de Iraklılık kimliğinin özellikle işgalin ilk birkaç yılının ardından toplumsal anlamda etki sahibi olmaya devam ettiği söylenebilir. Öncelikle, Iraklıların çoğunluğu, Irak'nn bütünlüğüne zarar vereceği için federalizme büyük oranda karşıydı ve Iraklıları bir halk olarak görmekteydi. ${ }^{87}$ Mesela, Pechter' in 2004 yılında yaptı̆̆ 1 bir ankette Iraklıların yüzde 56's1 Irak'ın birleşik bir ülke olarak kalması gerektiğini savunmuştur. ${ }^{88}$ Benzer şekilde, el-Hekim 2005 yazında güneydeki Şii vilayetler için federalizm kampanyası başlatırken, bir başka Şii lider Mukteda el-Sadr'ın federalizme şiddetli karşı çıkışları olmuştur. Aynı zamanda birçok Iraklı, sürgünden gelen seçkinleri dişarıdan gelmiş yabancılar olarak görmüştür; ${ }^{89}$ nitekim bu, elSadr'ın yeni seçkinlere yönelik söylemlerinde de hedef alınan bir durumdu. Diğer taraftan Nüfus Çalışmaları Merkezi'nin anketine göre, kendini her şeyden önce Iraklı olarak tanımlayanların oranı, Aralık 2004'te yüzde $23^{\prime} \mathrm{ken}$, Temmuz $2007^{\prime}$ de yüzde $59^{\prime}$ du..$^{90}$ Yine, Aralı 2004 'teki ankette

85 Adeed Dawisha, “Iraq's Year of Voting Dangerously," Journal of Democracy 17, no. 2 (2006): 93-94.

86 "Iraq Shias Demand Autonomy," The Guardian, August 11, 2005, https://www. theguardian.com/world/ 2005/aug/11/iraq1.

87 Haddad, and Rizvi, "Fitting Baghdad in," 51-74.

88 "Survey of Iraqi Public Opinion," International Republican Institute, accessed December 11, 2018, http://www.iri.org/sites/default/files/2004-09-07-Iraq\%20 Poll\%20July\%20August.pdf.

89 Haddad, and Rizvi, "Fitting Baghdad in," 66.

90 Mansoor Moaddel, "Religious Regimes and Prospects for Liberal Politics: Futures of Iran, Iraq, and Saudi Arabia," Population Studies Center (2008): 17. 
Iraklıların yüzde 85 'i Iraklı olmaktan az ya da çok gurur duyduklarını belirtirken, Temmuz 2007'de yapılan ankette Iraklı olmaktan gurur duymayan katılımcı oranı yalnızca yüzde 1'di. ${ }^{91} \mathrm{Bu}$ arada, ülkenin içerisinde bulunduğu iç savaş ortamında Temmuz 2007'de Irak millî futbol takımının Asya Kupası finalinde rakibi Suudi Arabistan'1 mağlup ederek şampiyon olmas1, yüzbinlerce Iraklıyı sokaklara dökmüştür. ${ }^{92}$ Diğer taraftan, devletin giriştiği düzen harekâtları, ülke bütünlüğünün korunmasında kritik rol oynamıştır. 2008 itibarıyla Nuri el-Maliki hükümeti, bir yandan Amerikan desteğiyle güneyde el-Sadr milislerinin üzerine gidip güneydeki milis kontrolünü zayıflatmış, diğer yandan Sahva hareketinin desteğiyle Sünni bölgelerde el-Kaide'yi bozguna uğratıp devlet kontrolünü artırmıştır.

$\mathrm{Bu}$ gelişmelere koşut olarak, Irakl1lık kimliğinin yükselen profilinin en çarpıcı örnekleri ise 2009 yerel seçimleri ve 2010 genel seçimlerinde görülmüştür. 2009 seçimlerine giden yolda Başbakan el-Maliki, Birleşik Irak İttifakı'ndan ayrılarak Kanun Devleti Koalisyonunu kurmuş ve geliştirdiği Irak milliyetçisi söylemle 2009 yerel seçimlerinde geniş çaplı bir başarı elde etmiştir. ${ }^{93} 2010$ seçimlerine giden süreçte ise kampanyaların ve koalisyonların önemli tartışmaları olarak, yabancı devletlerle (özellikle ABD ve İran'la) kurulacak ilişkiler (ve bu devletlerin Irak'ın iç işlerine müdahalesi), Irak'ın Arap dünyasına yeniden entegrasyonu, Sahva hareketinin Irak güvenlik güçlerine dâhli, Kerkük'ün statüsü ve federalizm gibi Irak'ın topraksal bütünlüğüne, kimliğine ve egemenliğine dair meseleler öne çımıştır. ${ }^{94} \mathrm{Bu}$ süreçte el-Maliki, eski ittifakıyla arasını daha fazla açmaya çalışmış, mezhepçi ayrımları açıktan açığa kınamış, mezhep ötesi politikalar yapma çağrısında bulunmuş, mezhep ötesi ittifakını genişletmek için birçok seküler ve Sünni liderle müzakerelere girişmiştir (ancak önemli

91 Mansoor Moaddel, Mark Tessler and Ronald Inglehart, "Foreign Occupation and National Pride: The Case of Iraq," Population Studies Center (2008): 22.

92 "Iraq in Historic Asian Cup Win," Al Jazeera English, July 29, 2007, https://www. aljazeera.com/focus/2007afcasiancup/2007/07/2008525184927362150.html; Don Riddell and Eoghan Macguire, "Ten Years On: How Iraq's Soccer Stars Brought Warring Nation Together," CNN, July 28, 2017, https://edition.cnn.com/2017/07/28/ football/iraq-asia-cup-2007-anniversary/index.html.

93 David Kenner and Andrew Swift, "The Definitive Guide to the Iraqi Elections," Foreign Policy, March 4, 2010, https://foreignpolicy.com/2010/03/04/the-definitiveguide-to-the-iraqi-elections/.

94 Lukitz, "Nationalism in Post-Imperial Iraq," 7-8. 
seküler ve Sünni figürleri buna dâhil edememiştir). ${ }^{95}$ Dahas1, daha önce Şiiler için güneyde özerk bir bölge oluşturulmasının propagandasını yapan el-Hekim kanadı, şimdi Bağdat'ta güçlü bir hükümetten yana tercihini ilan etmiş, 2010 seçimlerine giderken federalizmi açıkça savunan tek grup ise Kürtler olmuştur. ${ }^{96}$ Ayrıca, el-Hekim'in ve el-Sadr'ın başını çektiği Irak Millî İttifakı'nda "mezhepçilikten nefret ettiklerine" ve "Irak'ın onuru ve birliği için çalışacaklarına" dair söylemler yükselirken, Sünni Tevafuk grubu da yalnızca Sünni bölgelere değil tüm Irak’a seslenmeyi ve hizmet etmeyi vaat etmiştir. ${ }^{97}$ Seküler Irak milliyetçisi İyad Allavi'nin seçim kampanyası söylemi, "Müslüman ile gayri Müslim ya da Şii ile Sünni arasında fark olmadığı" üzerine kuruluydu ve karşılık bulmuştur. ${ }^{98}$ El-Maliki hükümetini yolsuzluk ve kamu hizmetlerinde yaşanan aksamalar nedeniyle de eleştiren İyad Allavi'nin partisi el-Irakiye, 91 sandalyeyle birinci gelmiş ve hem 6 sandalye kazanabilen Tevafuk'un Sünni bölgelerdeki popülerliğini yok etmiş hem de Şii bölgelerden oy almıştır. Birleşik Irak İttifakı'ndan ayrilan ve 2005 'ten beri başbakan olan el-Maliki'nin Kanun Devleti Koalisyonu, 89 sandalyeyle ikinci gelmiştir. 2005'teki Birleşik Irak İttifakı'nın diğer uzantısı olan ve mezhepçi eğilimleriyle öne çıkan Irak Millî İttifak1 ise 70 sandalyeyle üçüncü gelmiştir.99

Ancak bu kez de bir başka seçkin uygulamaları dizisi, toplumda yabancılaşmayı yoğunlaştırmıştır. Sünnilerin el-Irakiye listesi aracılığıyla ulaştıkları siyasî hareketlilik seviyesi, otoriter eğilimli el-Maliki kanadında mezhepçi popülizmi ve otoriter ivmeyi yükseltmiştir. Seçimlerde ikinci gelse de, İran'ın arabuluculuk girişimleriyle hükümet kurmayı başaran elMaliki, tekrar Şii milislere yönelmiş, Sünni cumhurbaşkanı yardımcısı Tarık el-Haşimi hakkında terörizm suçlamasıyla kovuşturma başlatmıştır. ${ }^{100}$ El-Maliki aynı zamanda, güneyde el-Sadr hareketine karşı kampanyasın-

\footnotetext{
95 Dawisha, "Iraq: A Vote Against Sectarianism," 29-30.

96 Dawisha, "Iraq: A Vote Against Sectarianism," 33.

97 Dawisha, "Iraq: A Vote Against Sectarianism," 34.

98 Tim Arango, "Ex-Leader Is Top Rival to Premier in Iraq Vote," The New York Times, March 5, 2010, https://www.nytimes.com/2010/03/06/world/middleeast/06allawi. html.

99 Andrea Plebani, "Iraq towards 2014 Elections: A Socio-Political Perspective," ISPI Analysis 196 (2013): 9.
}

100 Raymond Hinnebusch, "State Deconstruction in Iraq and Syria," PVS Politische Vierteljahresschrift 57, no. 4 (2016): 560-585. 
da kendisine yardımcı olan Şii aşiretleri Irak Güvenlik Güçleri'ne entegre ederken, Sünni Sahva hareketinin entegrasyonunu reddetmiş, Sahva hareketinin elinde bulundurduğu güce şüpheyle yaklaşarak Sahva liderlerini tutuklamış, 2011'de Arap İsyanları'ndan alınan ilhamla ülke genelinde ç1kan geniş çaplı protesto gösterilerine özellikle Sünni bölgelerde şiddet uygulayarak ve önemli Sünni siyasetçileri tutuklayarak karş11ık vermiştir. ${ }^{101}$ Böylece Sünni Araplar, el-Maliki'nin yükselen popülist otoriter eğilimleriyle gitgide yabancılaşmış ve Irak'ın toprak bütünlüğünü savunan eski söylemlerinden koparak ayrılıkçı bir söylem oluşturmaya başlamışlardır ki 2014'te halifelik ilan eden IŞíD'e yaklaşımları bu çerçeveden okunabilir. ${ }^{102}$ IŞ่iD'in yükselişiyle el-Maliki hükümetinin Sahva hareketini yeniden canlandırma girişimi, aynı hükümetin "Hüseyin ile Yezid arasındaki bir mücadele" olarak resmettiği Sünni ayaklanmalarıyla sonuçlanmıştır. ${ }^{103}$ Böylece, bir yandan Irak'ın mezhepçileşme süreci hızlanırken, diğer yandan Sünni kanadının ayrılıkçı söylemleri artmıştır. Diğer taraftan, bu zafiyet sürecinde Kürtler, başta Kerkük olmak üzere Irak hükümetiyle aralarında ihtilaf konusu olan bölgelerde kontrol sağlamışlardır. IŞSiD'in geri çekilmesinin tamamlandığı Eylül 2017'de, 2003'ten beri ayrıcalıklı bir istikrar bölgesi olarak sundukları ve şimdi sınırları genişleyip Kerkük'ü de içine almayı başarmış olan IKBY'nin bağımsızlığına yönelik referandum girişiminde bulunmuşlardır. ${ }^{104}$ Ancak başını Türkiye'nin, İran'ın ve Irak'ın çektiği uluslararası tecrit, yalnızca bağımsızlık girişimini akamete uğratmamış, aynı zamanda Irak yönetimi de IKBY'ye karşı çok daha zorlayıcı ve tehditkâr bir pozisyon elde etmiştir.

Öte yandan, ülkenin içerisinde bulunduğu siyasî kriz içerisinde 2016 bahar1, Bağdat'ın Tahrir Meydanı'nın mezhepçiliğe bir son verilmesini ve teknokrat bir hükümetin kurulmasını talep eden protestocularla dolduğu bir

101 Harith Hasan Al-Qarawee, "Iraq's Sectarian Crisis: A Legacy of Exclusion," The Carnegie Middle East Center (2014): 9-18; Phebe Marr, The Modern History of Iraq (Colorado: Westview Press, 2012), 324-326.

102 Hinnebusch, "State Deconstruction in Iraq and Syria," 571.

103 Fred H. Lawson, "Syria's Mutating Civil War and Its Impact on Turkey, Iraq and Iran," International Affairs 90, no. 6 (2014): 1360.

104 Damian Doyle and Tristan Dunning, "Recognizing Fragmented Authority: Towards a Post-Westphalian Security Order in Iraq," Small Wars \& Insurgencies 29, no. 3 (2018): 541. 
dönem olmuştur. ${ }^{105}$ Protestolar sırasında el-Sadr takipçileri, yalnızca Irak bayrağı taşımış, liderlerinin fotoğrafını açmamış ve mezhepçiliği kınayıp Irak'ın birliğini vurgulayan sloganlar atmışlardır. ${ }^{106} \mathrm{Bu}$ arada IŞiD süreci, bir taraftan otoriter eğilimli el-Maliki'yi başbakanlıktan uzaklaştırırken, diğer taraftan oluşan Şii mobilizasyon sebebiyle Sünnilerde yeni korkular oluşturarak sonlanmıştır. Aynı zamanda, her ne kadar Irak'ın parçalanma ihtimalinin çok daha yüksek seslerle dile getirildiği bu sancılı süreçte devlet zayıflığı tüm açıklığıyla sürse de, tüm bunların sonunda ülke bütünlüğü korunmuştur. Mayıs 2018 seçimlerinde ise, bir yandan Hadi el-Amiri gibi mezhepçi aktörler, diğer yandan da popüler Irak milliyetçiliği eğilimleri olan Mukteda el-Sadr gibi figürler öne çıkmıştır. Gelinen noktada Irak'ın kimlik meselesi, sürüncemede kalmaya devam etmektedir.

\section{Sonuç}

Yukarıda sunulan tarihsel anlatı çerçevesinde bu çalışma, birkaç farklı sonuca ulaşmaktadır. Öncelikle, Irak siyasetini tarihsel olarak okumanın ana paradigması olan yapaylık tezine karşılık Iraklılık üzerinden yapılan olan bir okuma, alternatif bir tarih ortaya çıkarmaktadır. Bu anlamda, bahsedilen tarih içerisinde Iraklılığın önemli bir ideolojik/kültürel etken olarak hazır bulunduğu görülmektedir. İkinci olarak, bu kimlik, Irak’taki diğer aidiyet boyutlarıyla çoğu zaman rekabet içerisinde olmuş, birçok vakada da bu boyutlarla iç içe geçmiştir ya da geçirilmeye çalışılmıştır. Dolay1sıyla Iraklılık anlatısı, yapaylık çerçevesinde sunulan anlatılardaki tarihsel kopuklukları kapatmaktadır. Üçüncü olarak, farklı rejimlerin, seçkinlerin, grupların Iraklılık projeksiyonlarında (hatta aynı aktörün farklı uygulamalarında dahi) önemli farklılaşmalar ve çelişkiler bulunmaktadır. Bir başka deyişle, bu kimliğin içeriği, anlamı ve tanımı konusunda bir uzlaşma oluşmamıştır ve kesintiler yaşanmıştır. Dördüncü olarak, Iraklılık kimliği, 1990'lara kadar büyük oranda devlet/seçkin pratikleri ve söylemleri üzerinden açılanırken 2003 sonrasında buna önemli bir toplumsal boyutun eklendiği gözlemlenmektedir. Nitekim, 1990'lara kadar devlet projesi ve doktrinasyonu çerçevesinde tanımlanan Iraklılık kimliği üzerinde toplumsal tepkilerin etkileri 2003 sonrasında daha fazla görülmektedir. Son ola-

\footnotetext{
105 Dawood, "Moats, Walls, and the Future of Iraqi National Identity," 13.

106 Dawood, "Moats, Walls, and the Future of Iraqi National Identity," 16.
} 
rak, özellikle 2003 işgali sonrasında popülerleşen ve mezhepsel farklılıklar üzerinden kurgulanan anlatı, Irak'ın basitleştirilmiş bir resmini çizmektedir ve mezhep kimliklerine özcü biçimde yaklaşmaktadır. Bu anlamda mezhepçilik anlatısı, 2003 işgali sonrasında net biçimde görülen federalizm karşıtı ve vatansever toplumsal dalgayı açıklamakta zorlanmaktadır. Netice itibarıyla, gelecek araştırmalarda farklı Orta Doğu ülkelerini devlet kimlikleri üzerinden karşılaştırarak farklılaşmaların ve benzeşmelerin şablonlarını oluşturmak, genel anlamda Orta Doğu'da kimlik meselesinin anlaşılmasına fayda sağlayacaktır.

\section{Kaynakça}

Abdi, Kamyar. "From Pan-Arabism to Saddam Hussein's Cult of Personality: Ancient Mesopotamia and Iraqi National Ideology." Journal of Social Archaeology 8, no. 1 (2008): 51-76.

Abdullah, Thabit A. J. Dictatorship, Imperialism and Chaos: Iraq since 1989. London and New York: Zed Books, 2006.

Anderson, Liam, and Gareth Stansfield. The Future of Iraq: Dictatorship, Democracy, or Division?. New York: Palgrave Macmillan, 2004.

Anscombe, Frederick F. "The Ottoman Empire in Recent International Politics - I: The Case of Kuwait." The International History Review 28, no. 3 (2006): 537-559.

Baram, Amatzia. "Mesopotamian Identity in Ba'thi Iraq." Middle Eastern Studies 19, no. 4 (1983): 426-455.

Baram, Amatzia. "Qawmiyya and Wataniyya in Ba'thi Iraq: The Search for a New Balance.” Middle Eastern Studies 19, no. 2 (1983): 188-200.

Baram, Amatzia. "Territorial Nationalism in the Middle East." Middle Eastern Studies 26, no. 4 (1990): 425-448.

Baram, Amatzia. Culture, History and Ideology in the Formation of Ba thist Iraq, 1968-89. London: Palgrave Macmillan, 1991.

Baram, Amatzia. "A Case of Imported Identity: The Modernizing Secular Ruling Elites of Iraq and the Concept of Mesopotamian-Inspired Territorial Nationalism, 1922-1992." Poetics Today 15, no. 2 (1994): 281-292. 
Batatu, Hanna. The Old Social Classes and the Revolutionary Movements in Iraq: A Study of Iraq's Old Landed and Commercial Classes and its Communists, Ba'thists, and Free Officers. Princeton: Princeton University Press, 1978.

Bruinessen, Martin van. "The Kurds between Iran and Iraq." MERIP Middle East Report 141 (1986).

Can, Serra. "The Iraqi Identity: Faisal's Unsolved Legacy.” Trames: A Journal of the Humanities and Social Sciences 22 no. 4 (2018): 389-405.

Catherwood, Christopher. Churchill's Folly: How Winston Churchill Created Modern Iraq. New York: Carrol \& Graf, 2004.

Cleveland, William L. The Making of an Arab Nationalist: Ottomanism and Arabism in the Life and Thought of Sati' al-Husri. Princeton: Princeton University Press, 1971.

Danilovich, Alex. Iraqi Federalism and the Kurds: Learning to Live Together. Surrey: Ashgate Publishing, 2014.

Dawisha, Adeed. "Democratic Attitudes and Practices in Iraq, 1921-1958." Middle East Journal 59, no. 1 (2005): 11-30.

Dawisha, Adeed, and Larry Diamond. "Iraq's Year of Voting Dangerously." Journal of Democracy 17, no. 2 (2006): 89-103.

Dawisha, Adeed. "The Unraveling of Iraq: Ethnosectarian Preferences and State Performance in Historical Perspective." Middle East Journal 62, no. 2 (2008): 219-230.

Dawisha, Adeed. Iraq: A Political History from Independence to Occupation. Princeton and New York: Princeton University Press, 2009.

Dawisha, Adeed. "National Identity and Sub-State Sectarian Loyalties in Iraq." International Journal of Contemporary Iraqi Studies 4, no. 3 (2010): 243-256.

Dawisha, Adeed. "Iraq: A Vote Against Sectarianism." Journal of Democracy 21 , no. 3 (2010): 26-40.

Dawisha, Adeed. "Identity and Political Survival in Saddam's Iraq." Middle East Journal 53, no. 4 (1999): 553-567.

Dawood, Ismaeel. "Moats, Walls, and the Future of Iraqi National Identity." Working Paper, Istituto Affari Internazionali, 2016. 
Dodge, Toby. Inventing Iraq: The Failure of Nation-Building and a History Denied. New York: Columbia University Press, 2003.

Dodge, Toby. "Iraqi Transitions: From Regime Change to State Collapse." Third World Quarterly 26, no. 4-5 (2005): 705-721.

Doyle, Damian, and Tristan Dunning. "Recognizing Fragmented Authority: Towards a Post-Westphalian Security Order in Iraq." Small Wars \& Insurgencies 29, no. 3 (2018): 537-559.

Eland, Ivan. Partitioning for Peace: An Exit Strategy for Iraq. Oakland: The Independent Institute, 2009.

Eppel, Michael. "The Hikmat Sulayman-Bakir Sidqi Government in Iraq, 1936-37, and the Palestine Question." Middle Eastern Studies 24, no. 1 (1988): 25-41.

Eppel, Michael. "The Elite, the Efendiyya, and the Growth of Nationalism and Pan-Arabism in Hashemite Iraq, 1921-1958." International Journal of Middle East Studies 30, no. 2 (1998): 227-250.

Farouk-Sluglett, Marion and Peter Sluglett. Iraq since 1958: From Revolution to Dictatorship. London and New York: I.B.Tauris, 2001.

Fattah, Hala and Frank Caso. A Brief History of Iraq. New York: Infobase Publishing, 2009.

Franzen, Johan. "The Problem of Iraqi Nationalism." National Identities 13, no. 3 (2011): 217-234.

Galbraith, Peter W. The End of Iraq: How American Incompetence Created a War Without End. New Jersey: Simon \& Schuster, 2006.

Gunter, Michael M. The Kurds of Iraq: Tragedy and Hope. New York: St. Martin's Press, 1992.

Haddad, Fanar, and Sajjad Rizvi. "Fitting Baghdad in." In An Iraq of its Regions: Cornerstones of a Federal Democracy, edited by Reidar Visser and Gareth Stansfield, 51-74. London: Hurst \& Company, 2007.

Haddad, Fanar. "The Terrorists of Today are the Heroes of Tomorrow: The Anti-British and anti-American Insurgencies in Iraqi History." Small Wars \& Insurgencies 19, no. 4 (2008): 451-483.

Haddad, Fanar. Sectarianism in Iraq: Antagonistic Visions of Unity. Oxford: Oxford University Press, 2011. 
Haddad, Fanar. "Sectarian Relations in Arab Iraq: Contextualising the Civil War of 2006-2007." British Journal of Middle Eastern Studies 40, no. 2 (2013): 115-138.

Hinnebusch, Raymond. "State Deconstruction in Iraq and Syria." PVS Politische Vierteljahresschrift 57, no. 4 (2016): 560-585.

Isakhan, Benjamin. "Targeting the Symbolic Dimension of Baathist Iraq: Cultural Destruction, Historical Memory, and National Identity." Middle East Journal of Culture and Communication 4 (2011): 257-281.

Ismael, Jacqueline S. and Shereen T. Ismael. "Iraqi Women under Occupation: From Tribalism to Neo-Feudalism." International Journal of Contemporary Iraqi Studies 1, no. 2 (2007): 2547-268.

Kirmanj, Sherko. "The Clash of Identities in Iraq." In Iraq Between Occupations: Perspectives from 1920 to the Present, edited by Amatzia Baram, Achim Rohde, and Ronen Reidel, 43-59. New York: Palgrave Macmillan, 2010.

Lawson, Fred H. "Syria's Mutating Civil War and Its Impact on Turkey, Iraq and Iran." International Affairs 90, no. 6 (2014): 1351-1365.

Leenders, Reinoud. "Strong States in a Troubled Region: Anatomies of a Middle Eastern Regional Conflict Formation." In Troubled Regions and Failing States: The Clustering and Contagion of Armed Conflict, edited by Kristian Berg Harpviken, 171-195. Oslo, Emerald Group Publishing, 2010.

Lukitz, Liora. Iraq: The Search for National Identity. London: Frank Cass, 1995.

Lukitz, Liora. "Nationalism in Post-Imperial Iraq: The Complexities of Collective Identity." Critical Review 21, no. 1 (2009): 5-20.

Marr, Phebe. "One Iraq or Many: What Has Happened to Iraqi Identity." In Iraq Between Occupations: Perspectives from 1920 to the Present, edited by Amatzia Baram, Achim Rohde, and Ronen Reidel, 15-41. New York: Palgrave Macmillan, 2010.

Marr, Phebe. The Modern History of Iraq. Colorado: Westview Press, 2012.

Mehmet Hurşî̀ Paşa. Seyâhatnâme-i Hudûd. Çevrimyazı Alâattin Eser. İstanbul: Simurg Kitapçılık ve Yayıncılık, 1997. 
Moaddel, Mansoor. "Religious Regimes and Prospects for Liberal Politics: Futures of Iran, Iraq, and Saudi Arabia." Research Report, Population Studies Center, 2008.

Moaddel, Mansoor, Mark Tessler and Ronald Inglehart. "Foreign Occupation and National Pride: The Case of Iraq." Research Report, Population Studies Center, 2008.

Plebani, Andrea. "Iraq towards 2014 Elections: A Socio-Political Perspective." ISPI Analysis 196 (2013).

al-Qarawee, Harith Hasan. "Iraq's Sectarian Crisis: A Legacy of Exclusion." The Carnegie Middle East Center (2014).

Reid, Donald Malcolm. "The Postage Stamp: A Window on Saddam Hussein's Iraq." Middle East Journal 47, no. 1 (1993): 77-89.

Simon, Reeva S. "The Teaching of History in Iraq before the Rashid Ali Coup of 1941." Middle Eastern Studies 22, no. 1 (1986): 37-51.

Sluglett, Peter. Britain in Iraq: Contriving King and Country. London and New York: I.B.Tauris, 2007.

Stokes, Doug. "The War Gamble: Understanding US Interests in Iraq." Globalizations 6, no. 1 (2009): 107-112.

al-Tikriti, Nabil. "Ottoman Iraq." The Journal of the Historical Society 7, no. 2 (2007): 201-211.

Tripp, Charles. A History of Iraq. Cambridge: Cambridge University Press, 2007.

Vinogradov, Amal. "The 1920 Revolt in Iraq Reconsidered: The Role of Tribes in National Politics." International Journal of Middle East Studies 3, no. 2 (1972): 123-139.

Visser, Reidar. "Proto-Political Conceptions of Iraq in Late Ottoman Times." International Journal of Contemporary Iraqi Studies 3, no. 2 (2009): 143-154.

Yıldız, Tunahan. "Mezhep Çatışmasına Bir Etnik Grup ve Yerel Bağlam Üzerinden Bakmak: Irak Türkmenleri ve Telafer Örneği." Türkiye Ortado$\breve{g u}$ Çalışmaları Dergisi 4, no. 2 (2017): 41-73.

Yıldız, Tunahan. "Modern Irak’ta Kürt-Türkmen İlişkileri." Avrasya Etüdleri 54, no. 2 (2018): 95-120. 
Zubaida, Sami. "The Fragments Imagine the Nation: The Case of Iraq." International Journal of Middle East Studies 34, no. 2 (2002): 205-215.

\section{İnternet Kaynakları}

Arango, Timç "Ex-Leader Is Top Rival to Premier in Iraq Vote." The New York Times, March 5, 2010, https://www.nytimes.com/2010/03/06/world/ middleeast/06allawi.html.

Central Intelligence Agency (CIA), Maps, https://www.cia.gov/library/ publications/resources/cia-maps-publications/Iraq.html.

Cooper, Paul. "Saddam's 'Disney for a Despot': How Dictators Exploit Ruins.” BBC, April 20, 2018, http://www.bbc.com/culture/story/20180419saddam-disney-for-a-despot-how-dictators-exploit-ruins.

Don Riddell, and Eoghan Macguire. "Ten Years On: How Iraq's Soccer Stars Brought Warring Nation Together." CNN, July 28, 2017, https://edition.cnn.com/2017/07/28/football/iraq-asia-cup-2007-anniversary/index.html.

International Republican Institute. "Survey of Iraqi Public Opinion." Accessed December 11, 2018. http://www.iri.org/sites/default/files/2004-0907-Iraq\%20Poll\%20July\%20August.pdf.

“Iraq in Historic Asian Cup Win.” Al Jazeera English, July 29, 2007, https:// www.aljazeera.com/focus/2007afcasiancup/2007/07/2008525184927362150.html.

"Iraq PM Slams U.S. Officer's Remarks on Partition." Al Arabiya English, August 13, 2015, http://english.alarabiya.net/en/News/middle-east/2015/08/13/Departing-U-S-army-chief-Iraq-may-have-to-bepartitioned.html.

"Iraq Shias Demand Autonomy." The Guardian, August 11, 2005, https:// www.theguardian.com/world/2005/aug/11/iraq1.

Kenner, David and Andrew Swift. "The Definitive Guide to the Iraqi Elections." Foreign Policy, March 4, 2010, https://foreignpolicy. com/2010/03/04/the-definitive-guide-to-the-iraqi-elections/.

Marco Vicenzino. "Iraq's Muddled Future." Huffington Post, April 17, 2015, https://www.huffingtonpost.com/marco-vicenzino/iraqs-muddledfuture_b_7081106.html. 
"Shia Alliance Wins Iraq Elections." The Guardian, January 20, 2006, https://www.theguardian.com/world/2006/jan/20/iraq.

"The Evolution of the Iraqi Flag." Al Arabiya English, May 26, 2015, http://english.alarabiya.net/en/perspective/infographics/2015/05/26/Theevolution-of-the-Iraqi-flag-.html. 